\title{
Amorphous Solid Dispersion Tablets Overcome Acalabrutinib pH Effect in Dogs
}

\author{
Deanna M. Mudie ${ }^{1, *(D)}$, Aaron M. Stewart ${ }^{1}{ }^{(1)}$, Jesus A. Rosales ${ }^{1,2}{ }^{2}$ Nishant Biswas ${ }^{1}$, Molly S. Adam ${ }^{1}$, \\ Adam Smith ${ }^{1}$, Christopher D. Craig ${ }^{1}$, Michael M. Morgen ${ }^{1}$ (D) and David T. Vodak ${ }^{1}$ \\ 1 Global Research \& Development, Lonza, Bend, OR 97703, USA; aaron.stewart@lonza.com (A.M.S.); \\ rosaleja@uw.edu (J.A.R.); nishantbb@gmail.com (N.B.); molly.adam@lonza.com (M.S.A.); \\ adam.smith@lonza.com (A.S.); chris.craig@lonza.com (C.D.C.); michael.morgen@lonza.com (M.M.M.); \\ david.vodak@lonza.com (D.T.V.) \\ 2 Pharmaceutics Department, University of Washington, Seattle, WA 98195, USA \\ * Correspondence: deanna.mudie@lonza.com
}

Citation: Mudie, D.M.; Stewart, A.M.; Rosales, J.A.; Biswas, N.; Adam, M.S.; Smith, A.; Craig, C.D.; Morgen, M.M.; Vodak, D.T. Amorphous Solid Dispersion Tablets Overcome Acalabrutinib pH Effect in Dogs. Pharmaceutics 2021, 13, 557. https://doi.org/10.3390/ pharmaceutics13040557

Academic Editors: Vitaliy Khutoryanskiy and Hisham Al-Obaidi

Received: 29 March 2021

Accepted: 13 April 2021

Published: 15 April 2021

Publisher's Note: MDPI stays neutral with regard to jurisdictional claims in published maps and institutional affiliations.

Copyright: (c) 2021 by the authors. Licensee MDPI, Basel, Switzerland. This article is an open access article distributed under the terms and conditions of the Creative Commons Attribution (CC BY) license (https:// creativecommons.org/licenses/by/ $4.0 /)$.
Abstract: Calquence ${ }^{\circledR}$ (crystalline acalabrutinib), a commercially marketed tyrosine kinase inhibitor (TKI), exhibits significantly reduced oral exposure when taken with acid-reducing agents (ARAs) due to the low solubility of the weakly basic drug at elevated gastric $\mathrm{pH}$. These drug-drug interactions (DDIs) negatively impact patient treatment and quality of life due to the strict dosing regimens required. In this study, reduced plasma drug exposure at high gastric $\mathrm{pH}$ was overcome using a spraydried amorphous solid dispersion (ASD) comprising 50\% acalabrutinib and 50\% hydroxypropyl methylcellulose acetate succinate (HPMCAS, H grade) formulated as an immediate-release (IR) tablet. ASD tablets achieved similar area under the plasma drug concentration-time curve (AUC) at low and high gastric $\mathrm{pH}$ and outperformed Calquence capsules 2.4-fold at high gastric $\mathrm{pH}$ in beagle dogs. In vitro multicompartment dissolution testing conducted a priori to the in vivo study successfully predicted the improved formulation performance. In addition, ASD tablets were $60 \%$ smaller than Calquence capsules and demonstrated good laboratory-scale manufacturability, physical stability, and chemical stability. ASD dosage forms are attractive for improving patient compliance and the efficacy of acalabrutinib and other weakly basic drugs that have $\mathrm{pH}$-dependent absorption.

Keywords: acalabrutinib; amorphous solid dispersion; acid-reducing agent; bioavailability enhancement; kinase inhibitor; $\mathrm{pH}$ effect; proton pump inhibitor; spray drying

\section{Introduction}

Calquence $^{\circledR}$ is a commercially marketed kinase inhibitor used as second-line therapy for adult patients seeking treatment for mantle cell lymphoma, chronic lymphocytic leukemia, or small lymphocytic lymphoma [1]. The active pharmaceutical ingredient (API) in Calquence is the crystalline Form I of acalabrutinib, which is a diprotic weak base with $\mathrm{pK}_{\mathrm{a}}$ values of 3.5 and 5.8 [2]. It is a Biopharmaceutics Classification System (BCS) Class 2 drug with low intrinsic solubility and a moderate $\log \mathrm{P}[2,3]$. The chemical structure and compound properties of acalabrutinib are shown in Figure 1 and Table 1, respectively.

Calquence has clinically meaningful drug-drug interactions (DDIs) with acid-reducing agents (ARAs) such as proton pump inhibitors (PPIs), where concomitant use results in reduced area under the plasma drug concentration-time curve (AUC) values [4]. For example, coadministration of Calquence with $40 \mathrm{mg}$ of the PPI omeprazole for 5 days decreased AUC by $43 \%$ in healthy subjects [1]. According to the Food and Drug Administration (FDA) label for Calquence, patients must avoid coadministration with PPIs and stagger dosing with histamine $\mathrm{H}_{2}$ receptor antagonists $\left(\mathrm{H}_{2} \mathrm{RAs}\right)$ and antacids [1]. Because ARAs are commonly prescribed to cancer patients, these DDIs can undermine efficacy and patient compliance due to the complex dosing schedules required [5]. 


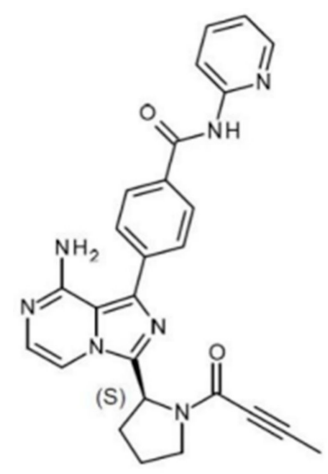

Figure 1. Acalabrutinib chemical structure.

The mechanism of reduced performance of acalabrutinib crystalline Form I when taken with ARAs is decreased solubility at the elevated gastric $\mathrm{pH}$ levels that occur when ARAs are administered, referred to here as the "ARA effect" [4,6]. The reduced solubility of the weakly basic drug decreases dissolution, which decreases absorption across the intestinal membrane and increases the extent of dose metabolized in humans [2,7]. This gastric $\mathrm{pH}$-dependent mechanism that occurs with weakly basic drugs is the most common DDI for ARAs. However, natural variations in gastric $\mathrm{pH}$ also cause undesirable variability in Calquence performance, irrespective of the use of ARAs [4,8-10].

Table 1. Acalabrutinib Form I physicochemical properties.

\begin{tabular}{cc}
\hline Compound Property & Value \\
\hline Molecular weight $(\mathrm{g} / \mathrm{mol})$ & 465.5 \\
$\mathrm{pK}$ & in physiological range \\
$\log \mathrm{P}$ & 3.5 (basic) and 5.8 (basic) ${ }^{\mathrm{a}}$ \\
Melting temperature $\left(\mathrm{T}_{\mathrm{m}}\right)\left({ }^{\circ} \mathrm{C}\right)$ & $2.0^{\mathrm{a}}$ \\
Glass-transition temperature $\left(\mathrm{T}_{\mathrm{g}}\right)\left({ }^{\circ} \mathrm{C}\right)$ & $133^{\mathrm{c}}$ \\
Crystalline intrinsic solubility $(\mu \mathrm{g} / \mathrm{mL})$ & $48^{\mathrm{a}}$ \\
\hline
\end{tabular}

a Reference [2]. ${ }^{\mathrm{b}}$ Reference [11]. ${ }^{\mathrm{c}}$ Measured in house using modulated differential scanning calorimetry (mDSC). Refer to Appendix A.1 for method information.

To overcome the ARA effect, a spray-dried amorphous solid dispersion (ASD) was developed and formulated as an immediate-release (IR) tablet. ASD technologies are used to enhance solubilization and increase the bioavailability of poorly soluble drugs [12]. The amorphous drug form has higher solubility than the crystalline drug form due to its higher activity [13]. Since the amorphous form is thermodynamically unstable, it is typically formulated as an ASD with a polymer to stabilize the high free energy state [14].

Since the ARA effect is caused by the decreased solubility of acalabrutinib crystalline Form I at elevated gastric pH, it was hypothesized that an ASD of acalabrutinib could increase API solubility enough to provide rapid and high extent of gastrointestinal (GI) dissolution of the API at high and low gastric $\mathrm{pH}$ values (i.e., in the presence and absence of ARAs). Furthermore, achieving complete absorption in the presence of ARAs would provide limited potential for increased absorption at low, fasted-state gastric $\mathrm{pH}$ where the API is more soluble. Achieving similar AUC values under both conditions could thereby mitigate the ARA effect and potentially negate the DDI seen with crystalline Form I acalabrutinib.

The goal of this study was to demonstrate mitigation of the ARA effect in a beagle dog model using acalabrutinib ASD IR tablets at a $100 \mathrm{mg}$ dose. A 50/50 (\% w/w) ASD containing acalabrutinib and hydroxypropyl methylcellulose acetate succinate (HPMCAS, HF grade) was prepared using a laboratory (kilogram)-scale spray dryer and incorporated into ASD IR tablets. In vivo tests were conducted in fasted beagle dogs (1) pretreated with pentagastrin to increase gastric acid secretion and lower stomach $\mathrm{pH}$ or (2) pretreated with famotidine (an ARA) to decrease gastric acid secretion and elevate stomach pH. ASD IR 
tablets and commercially available Calquence capsules were administered to the dogs and the results were compared.

In addition to the in vivo study, ASD tablets and Calquence capsules were tested and compared in an in vitro multicompartment dissolution apparatus designed to reflect average gastrointestinal physiology in beagle dogs pretreated with pentagastrin or famotidine. Further, physical and chemical stability of the ASD, and chemical stability of the ASD tablet were assessed to demonstrate the integrity of amorphous acalabrutinib in the ASD tablet.

\section{Materials and Methods}

\subsection{Material Sourcing}

Acalabrutinib (CAS 1420477-60-6, >98\% purity) was purchased from LC Laboratories (Woburn, MA, USA). HPMCAS-HF (Aqoat, HF grade) was purchased from Shin-Etsu Chemical Co., Ltd. (Tokyo, Japan). Hydrochloric acid ( $\mathrm{HCl}$ ), sodium acetate, sodium phosphate, potassium phosphate, and sodium chloride $(\mathrm{NaCl})$ were purchased from Sigma Aldrich Chemical Company (St. Louis, MO, USA). Ammonium acetate was purchased from Thermo Fisher Scientific (Waltham, MA, USA). Fasted-state simulated intestinal fluid (FaSSIF) powder was purchased from Biorelevant.com Ltd. (London, UK). Methanol (HPLC grade) was purchased from Honeywell (Morris Plains, NJ, USA). Calquence capsules were purchased from Drug World (Cold Spring, NY, USA). Avicel PH-101 (microcrystalline cellulose) was purchased from FMC Corporation (Philadelphia, PA, USA). Pearlitol 25 (mannitol) was purchased from Roquette America (Geneva, IL, USA). Ac-Di-Sol (croscarmellose sodium) was purchased from Dupont (Wilmington, DE, USA). Cab-O-Sil M5P (fumed silica) was purchased from Cabot Corporation (Alpharetta, GA, USA). Magnesium stearate was purchased from Macron Fine Chemicals / Avantor (Radnor, PA, USA). Covance Laboratories (Madison, WI, USA) purchased pentagastrin from Sigma Aldrich Chemical Company and famotidine from Kirkland Signature (Kirkland, WA, USA) for use in in vivo testing.

\subsection{ASD Manufacturing and Characterization}

A $32 \mathrm{~g}$ batch of 50/50 (\% w/w) acalabrutinib/HPMCAS-HF grade (Aqoat ${ }^{\circledR}$, Shin-Etsu Chemical Co., Ltd., Tokyo, Japan) ASD was manufactured using a customized laboratoryscale spray dryer $(0.3 \mathrm{~m}$ chamber diameter) capable of drying-gas flow rates of up to $35 \mathrm{~kg} / \mathrm{h}$. This ASD composition was selected as the lead after screening several different dispersion polymers and one additional drug loading (data to be provided in a future publication). Methanol was used as the spray solvent. The total solids loading in the spray solution was $5.4 \mathrm{wt} \%$. Solutions were sprayed using a Schlick 2.0 pressure-swirl nozzle (Model 121, 200- $\mu \mathrm{m}$ orifice, Schlick Americas, Bluffton, SC, USA) at an outlet temperature of 45 to $50^{\circ} \mathrm{C}$ and an inlet temperature of 142 to $150^{\circ} \mathrm{C}$.

After material was collected in a cyclone, residual solvent was removed in a secondary drying step using a vacuum dryer (Model TVO-2, Cascade TEK, Cornelius, OR, USA) for $20 \mathrm{~h}$ at $40{ }^{\circ} \mathrm{C}$ with a nitrogen sweep gas $(-60 \mathrm{cmHg}$, 3 standard liters per minute). Solvent removal was confirmed to be below International Council for Harmonization (ICH) thresholds for methanol (<3000 ppm) using gas chromatography (GC). The ASD was analyzed using modulated differential scanning calorimetry (mDSC) to ensure a single $\mathrm{T}_{\mathrm{g}}$ as an indication of drug-polymer homogeneity. Powder X-ray diffraction (PXRD) was used to verify the ASD was amorphous. Scanning electron microscopy (SEM) was used to visually identify potential changes in morphology or the presence of surface crystals. Method details can be found in Appendix A.1.

\subsection{ASD Tablet Manufacturing and Characterization}

The ASD IR tablets, which had a $100 \mathrm{mg}$ unit dosage strength, a $400 \mathrm{mg}$ total mass and a drug loading of $25 \mathrm{wt} \%$, were manufactured using the $50 / 50(\% w / w)$ acalabrutinib/HPMC AS-H ASD. ASD tablet information is provided in Table 2. 
Table 2. Detailed ASD tablet formulation and composition.

\begin{tabular}{|c|c|c|}
\hline Function & Ingredient & Tablet Fraction $(w t \%){ }^{a}$ \\
\hline ASD & $\begin{array}{c}\text { Intragranular } \\
50 / 50 \text { acalabrutinib/Aqoat } \\
\text { (HPMCAS-HF) }\end{array}$ & 50.0 \\
\hline Ductile filler & Avicel ${ }^{\circledR}$ PH-101 & 14.3 \\
\hline Brittle filler & Pearlitol ${ }^{\circledR} 25$ & 28.7 \\
\hline Disintegrant & Ac-Di-Sol ${ }^{\circledR}$ & 6.0 \\
\hline Glidant & Cab-O-Sil ${ }^{\circledR}(\mathrm{M} 5 \mathrm{P})$ & 0.25 \\
\hline Lubricant & $\begin{array}{c}\text { Magnesium stearate } \\
\text { Extragranular }\end{array}$ & 0.25 \\
\hline Glidant & Cab-O-Sil & 0.25 \\
\hline Lubricant & $\begin{array}{l}\text { Magnesium stearate } \\
\text { Total tablet mass: }\end{array}$ & $\begin{array}{c}0.25 \\
400 \mathrm{mg}\end{array}$ \\
\hline
\end{tabular}

a Tablets were made using $11 \mathrm{~mm}$ standard round concave (SRC) tooling.

ASD tablets were manufactured using a small-scale, semi-manual dry-granulation process. The ASD and intragranular excipients (see Table 2) were blended in a Turbula blender (Glen Mills Inc., Clifton, NJ, USA). The intragranular blend was compressed into slugs using a Manesty F3 single-station tablet press (Manesty Ltd., Knowsley, UK) with half-inch flat-faced tooling. Slugs were milled using a 1Zpresso Pro coffee grinder (1Zpresso, New Taipei City, Taiwan) at a setting of 4.5. The milled slugs were blended with extragranular excipients (see Table 2) to create a final blend. The final blend was compressed to a target tensile strength of $2 \mathrm{MPa}$ using a Manesty F3 single-station tablet press with $11 \mathrm{~mm}$ SRC tooling. Complete manufacturing details can be found in Appendix A.2.

Tablet disintegration rates were determined in $\mathrm{HCl}(\mathrm{pH} 2)$ and phosphate-buffered saline ( $\mathrm{pH} 6,67 \mathrm{mM}$ phosphate) in a U.S. Pharmacopeia (USP) disintegration apparatus (ZT-71 disintegration tester, Erweka, Heusenstamm, Germany) using three replicates.

\subsection{Stability}

The ASD was stored at $40{ }^{\circ} \mathrm{C} / 75 \%$ relative humidity (RH) to assess physical and chemical stability under accelerated storage conditions. Initial ASD samples and aged ASDs were analyzed for crystallinity using PXRD, thermal properties using $\mathrm{MDSC}$, changes in morphology or presence of surface crystals using SEM, and chemical degradation by reverse-phase high-performance liquid chromatography (RP-HPLC). The ASD and ASD tablets were stored at ambient and refrigerated conditions to assess the chemical stability at nonaccelerated conditions. Initial and aged ASD samples were analyzed for total related substances using RP-HPLC. See Appendix A.3 for method details.

\subsection{In Vitro Dissolution Testing}

The in vitro dissolution performance of the ASD tablet and the commercially available Calquence capsule was evaluated using a controlled-transfer dissolution (CTD) apparatus containing stomach, duodenum, and jejunum/waste compartments $[15,16]$. The in vitro testing parameters were selected based on acalabrutinib physicochemical properties; the dose; and the average physiology of fasted beagle dogs (1) pretreated with pentagastrin to increase gastric acid secretion and lower stomach $\mathrm{pH}$ and (2) pretreated with famotidine to decrease gastric acid secretion and elevate stomach $\mathrm{pH}$ [17-23]. Due to its basic $\mathrm{pK}_{\mathrm{a}} \mathrm{s}$ (3.5 and 5.8), acalabrutinib is expected to dissolve to a high extent in low-pH gastric environments and supersaturate upon emptying into the upper intestine [2]. A CTD test was used to evaluate the dissolution behavior of acalabrutinib in various gastric environments and maintain supersaturation upon emptying into an intestinal compartment. CTD test parameters are summarized in Table 3. 
Table 3. Summary of CTD in vitro testing parameters.

\begin{tabular}{cc}
\hline Parameter & Value \\
\hline Dose $(\mathrm{mg})$ & 100 \\
Dosing volume $(\mathrm{mL})$ & 50 \\
Dosing medium & Milli-Q water \\
Gastric resting medium & $\mathrm{HCl}(\mathrm{pH} 2)$ and $34 \mathrm{mM} \mathrm{NaCl}$ \\
Gastric secretion medium & $\mathrm{HCl}(\mathrm{pH} 6)$ and $34 \mathrm{mM} \mathrm{NaCl}$ \\
Gastric resting volume $(\mathrm{mL})$ & 50 \\
Gastric secretion rate $(\mathrm{mL} / \mathrm{min})$ & 2.4 \\
Gastric emptying half-life & 15 \\
(monoexponential) $(\mathrm{min})$ & Phosphate $(\mathrm{pH}$ 6.5) and FaSSIF powder a \\
Duodenal resting and secretion medium & 50 \\
Duodenal fluid volume $(\mathrm{mL})$ & 2.4 \\
Duodenal secretion rate $(\mathrm{mL} / \mathrm{min})$ & Gastric emptying and duodenal secretion \\
Duodenal emptying rate & Gastric and duodenal composition \\
Jejunal medium & Starts at 0 and increases to $419 \mathrm{~mL}$ at $90 \mathrm{~min}$ \\
Jejunal volume &
\end{tabular}

Fiber-optic UV probe detection was used to measure acalabrutinib concentrations in the stomach and duodenum compartments of the CTD apparatus. Before the experiment, unique calibration curves were generated for each UV probe ( $2 \mathrm{~mm}$ path length) by delivering aliquots of a known amount of stock acalabrutinib solution $(10 \mathrm{mg} / \mathrm{mL}$ acalabrutinib in methanol) to $50 \mathrm{~mL}$ of gastric or intestinal medium held at $37^{\circ} \mathrm{C}$. To begin dosing, a single $100 \mathrm{mg}$ ASD tablet or $100 \mathrm{mg}$ Calquence capsule was placed in a hanging basket and submerged in the stomach compartment along with $50 \mathrm{~mL}$ water (for a $100 \mathrm{~mL}$ total volume in the stomach compartment). This achieves a dose concentration of $1 \mathrm{mg} / \mathrm{mL}$ acalabrutinib in the stomach compartment at the onset of the experiment. The ASD tablet was agitated for $1 \mathrm{~min}$ and the Calquence capsule was agitated for $10 \mathrm{~min}$ before initiating gastric emptying to allow dosage-form disintegration and dispersal. Each compartment was stirred at $150 \mathrm{rpm}$ and held at $37^{\circ} \mathrm{C}$ by circulating water through jacketed glass vessels. The dissolution performance in each compartment was monitored using Pion Rainbow $^{\mathrm{TM}}$ UV probes (Pion Inc., Billerica, MA, USA) at 360 to $364 \mathrm{~nm}$ in the stomach and the duodenum compartments. The apparent concentrations measured consisted of (1) drug dissolved in aqueous medium, (2) drug partitioned into bile-salt micelles (when present) as micelle-bound drug. Drug concentrations were monitored for $90 \mathrm{~min}$ after gastric emptying started. All samples were analyzed in duplicate.

\subsection{Pharmacokinetic (PK) Study}

ASD tablets and Calquence capsules were evaluated for in vivo performance in beagle $\operatorname{dogs}(n=6)$ at a $100 \mathrm{mg}$ dose strength. The study was conducted by Covance Laboratories Inc. (Madison, WI, USA) in accordance with the protocol, protocol amendment, and Covance standard operating procedures (SOPs). All procedures were in compliance with the Animal Welfare Act Regulations (9 CFR 3).

Calquence capsules were stored at room temperature according to package directions and ASD tablets were stored at 2 to $8{ }^{\circ} \mathrm{C}$ prior to dosing. The study design is shown in Table 4. Dogs were pretreated with intramuscular pentagastrin in Phases 1 and 3 to increase gastric acid secretion and lower stomach $\mathrm{pH}$ (representing fasted human gastric $\mathrm{pH}$ ) [17]. Dogs were pretreated with oral famotidine in Phases 2 and 4 to decrease gastric acid creation and raise stomach $\mathrm{pH}$ (representing the gastric $\mathrm{pH}$ of fasted humans taking ARAs) $[17,18]$.

The purebred, non-naive beagle dogs used in the study weighed 8.9 to $10.7 \mathrm{~kg}$ and were 1 to 2 years in age. For each phase, animals were fasted overnight before dose administration. Food was returned to the animals at approximately $4 \mathrm{~h}$ after dosing. 
For each phase, a flush with approximately $10 \mathrm{~mL}$ water was administered to facilitate swallowing of the tablet or capsule dosage form.

Table 4. In vivo study design.

\begin{tabular}{cccc}
\hline Phase $^{\text {a }}$ & Test Article & Pretreatment & Dosage Form per Animal \\
\hline 1 & Acalabrutinib ASD & Pentagastrin $^{\mathrm{b}}$ & 1 tablet \\
2 & Acalabrutinib ASD & Famotidine $^{\mathrm{c}}$ & 1 tablet \\
3 & Calquence & Pentagastrin $^{\mathrm{b}}$ & 1 capsule \\
4 & Calquence & Famotidine $^{\mathrm{c}}$ & 1 capsule \\
\hline
\end{tabular}

a Each phase consisted of 6 dogs at a $100 \mathrm{mg}$ target acalabrutinib dose level with a 7 day washout between phases. ${ }^{\mathrm{b}}$ For Phases 1 and 3, animals received a subcutaneous injection of pentagastrin $(6 \mathrm{mg} / \mathrm{kg} / 60 \mathrm{mg} / \mathrm{mL} / 0.1 \mathrm{~mL} / \mathrm{kg})$ approximately $30 \mathrm{~min}$ before test article administration. ${ }^{c}$ For Phases 2 and 4, animals received a $40 \mathrm{mg}$ oral dose of famotidine (two $20 \mathrm{mg}$ tablets) approximately $60 \mathrm{~min}$ before test article administration.

For each phase, blood (approximately $1 \mathrm{~mL}$ ) was collected from each animal from a jugular vein into tubes containing $\mathrm{K}_{2}$ EDTA before dosing at $0.25,0.5,1,2,4,8,12$, and $24 \mathrm{~h}$ after dosing. Blood was maintained in chilled cryogenic racks before centrifugation to obtain plasma. Centrifugation began within $1 \mathrm{~h}$ of collection. Plasma was placed into 96-well tubes with barcode labels. Plasma was maintained on dry ice before storage at approximately $-70^{\circ} \mathrm{C}$.

Acalabrutinib concentrations in dog plasma were measured by liquid chromatographytandem mass spectrometry (LC-MS/MS) using a Sciex API-5000 system (Framingham, MA, USA) equipped with positive-ionization turbo ion spray. The concentrations of the samples were quantitated using a linear calibration curve that was prepared by diluting a stock solution of acalabrutinib in dimethylformamide at a concentration of $20 \mu \mathrm{g} / \mathrm{mL}$. The stock solution was diluted to a range of $1-1000 \mathrm{ng} / \mathrm{mL}$ in 1:1 acetonitrile:water and spiked with blank protein. An internal standard, consisting of labetalol dissolved at $200 \mathrm{ng} / \mathrm{mL}$ in acetonitrile, was used to ensure system suitability. The dog plasma samples were prepared for analysis by precipitating the protein in acetonitrile in a 96-well plate and diluting the supernatant in 1 equivalent of acetonitrile. HPLC analysis was conducted using a $50 \mathrm{~mm} \times 2 \mathrm{~mm}, 2.5 \mu \mathrm{m}$ pore size Phenomenex Luna C18(2) high-speed-technology (HST) column (Phenomenex, Torrance, CA, USA) at a flow rate of $0.6 \mathrm{~mL} / \mathrm{min}$. The mobile phases consisted of $15 \mathrm{mM}$ ammonium formate in water containing $0.1 \%$ formic acid and $0.1 \%$ formic acid in acetonitrile. During analysis, the column temperature was maintained at $50{ }^{\circ} \mathrm{C}$, whereas the sample compartment was maintained at $5^{\circ} \mathrm{C}$.

Pharmacokinetic parameters including maximum drug plasma concentration $\left(\mathrm{C}_{\max }\right)$, time to maximum plasma concentration $\left(\mathrm{T}_{\max }\right)$, AUC through $24 \mathrm{~h}\left(\mathrm{AUC}_{0-24}\right)$, and the AUC extrapolated to infinity $\left(\mathrm{AUC}_{0}-\mathrm{inf}\right)$ were determined for each individual subject using Microsoft Excel (Microsoft Corporation, Seattle, WA, USA). $\mathrm{AUC}_{0-24}$ and $\mathrm{AUC}_{0 \text {-inf }}$ were calculated using a linear trapezoidal method. Results of each individual subject were averaged to obtain the reported averages and standard deviations. $\mathrm{AUC}_{0 \text {-inf }}$ ratios (famotidine/pentagastrin) were calculated for ASD tablets and Calquence capsules. In

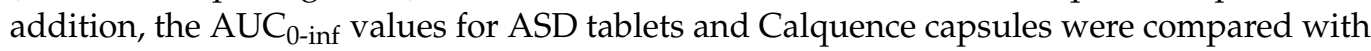
those of Calquence capsules after pentagastrin pretreatment, as were statistical $p$-values using a one-way analysis of variance (ANOVA) test for AUC relative to Calquence after famotidine pretreatment and Calquence after pentagastrin pretreatment.

\section{Results}

\subsection{ASD and Tablet Manufacturing and Characterization}

A 50/50 (\% w/w) acalabrutinib/HPMCAS-H ASD was spray dried with a high yield (97\% after secondary drying). The ASD contained $100 \mathrm{ppm}$ of residual methanol, well below the ICH threshold of $3000 \mathrm{ppm}$. Furthermore, the ASD was confirmed to be amorphous and homogenous by mDSC as evident by a single $\mathrm{T}_{\mathrm{g}}$ centered at $115.6 \pm 0.3^{\circ} \mathrm{C}$. PXRD showed no evidence of crystallinity, based on the absence of sharp diffraction peaks characteristic of crystalline acalabrutinib. SEM demonstrated that ASD particles were primarily collapsed 
spheres with no evidence of surface crystals. Complete characterization results can be found in Appendix A.4.

ASD tablets were successfully manufactured to a target tensile strength of $2 \mathrm{MPa}$. The compression pressure needed to achieve a $2 \mathrm{MPa}$ tensile strength was $78 \mathrm{MPa}$, with an average solid fraction of 0.80 . On average, the tablets were $4.9 \mathrm{~mm}$ thick and had a tablet volume of $370 \mathrm{~mm}^{3}$. This tablet volume is $60 \%$ smaller than the dosage form size of Calquence capsules, which have a calculated Size 1 capsule volume of $\sim 870 \mathrm{~mm}^{3}$.

Tablets disintegrated rapidly in the USP disintegration tester, with a $32 \pm 2 \mathrm{~s}$ disintegration time (average \pm standard deviation) at $\mathrm{pH} 2$ and a $37 \pm 4 \mathrm{~s}$ disintegration time at $\mathrm{pH} 6$.

\subsection{Stability}

The ASD was stored at $40{ }^{\circ} \mathrm{C} / 75 \% \mathrm{RH}$ to assess physical and chemical stability when stored under accelerated conditions. The ASD showed good physical stability when stored at $40{ }^{\circ} \mathrm{C} / 75 \% \mathrm{RH} /$ open for 6 months, as indicated by a lack of sharp diffraction peaks by PXRD, a lack of particle fusion or other particle surface morphology changes by SEM micrographs, and a single $\mathrm{T}_{\mathrm{g}}$ by $\mathrm{mDSC}$ after aging at accelerated conditions. Although the ASD showed good physical stability at $40{ }^{\circ} \mathrm{C} / 75 \% \mathrm{RH}$, significant chemical degradation of the ASD was observed after storage for 12 weeks at $40{ }^{\circ} \mathrm{C} / 75 \% \mathrm{RH}$, with HPLC results showing a $780 \%$ increase in impurities.

The ASD and ASD tablet were stored at ambient and refrigerated conditions to assess chemical stability. Storage at refrigerated conditions with and without desiccant and at $25^{\circ} \mathrm{C} / 60 \% \mathrm{RH} /$ sealed with desiccant mitigated chemical degradation of the ASD and ASD tablet. For example, refrigerated storage for 12 weeks resulted in no increase in impurities for the ASD or ASD tablet. Storage at $25{ }^{\circ} \mathrm{C} / 60 \% \mathrm{RH} /$ sealed with desiccant for 12 weeks resulted in no increase in impurities for the ASD and only a $6 \%$ increase in impurities (total impurities $=0.69 \pm 0.00$ area $\%$ ) for the ASD tablet. Results and discussion can be found in Appendix A.5.

\subsection{Tablet In Vitro Dissolution Performance}

ASD tablets and Calquence capsules were tested in the CTD apparatus using $0.01 \mathrm{~N}$ $\mathrm{HCl}(\mathrm{pH} 2)$ as the gastric medium. As the dissolution results in Figure 2 show, dissolution of the ASD tablets and Calquence capsules were practically identical under conditions simulating fasted dogs treated with pentagastrin. Acalabrutinib is a weakly basic compound with $\mathrm{pK}_{\mathrm{a}} \mathrm{s}$ of 3.5 and 5.8. As a result of ionization, acalabrutinib has a high crystalline solubility at $\mathrm{pH}$. This high crystalline drug solubility drives rapid dissolution of both dosage forms in the gastric compartment and, upon transfer to the duodenal compartment, results in supersaturated drug concentrations and identical duodenal AUC values.
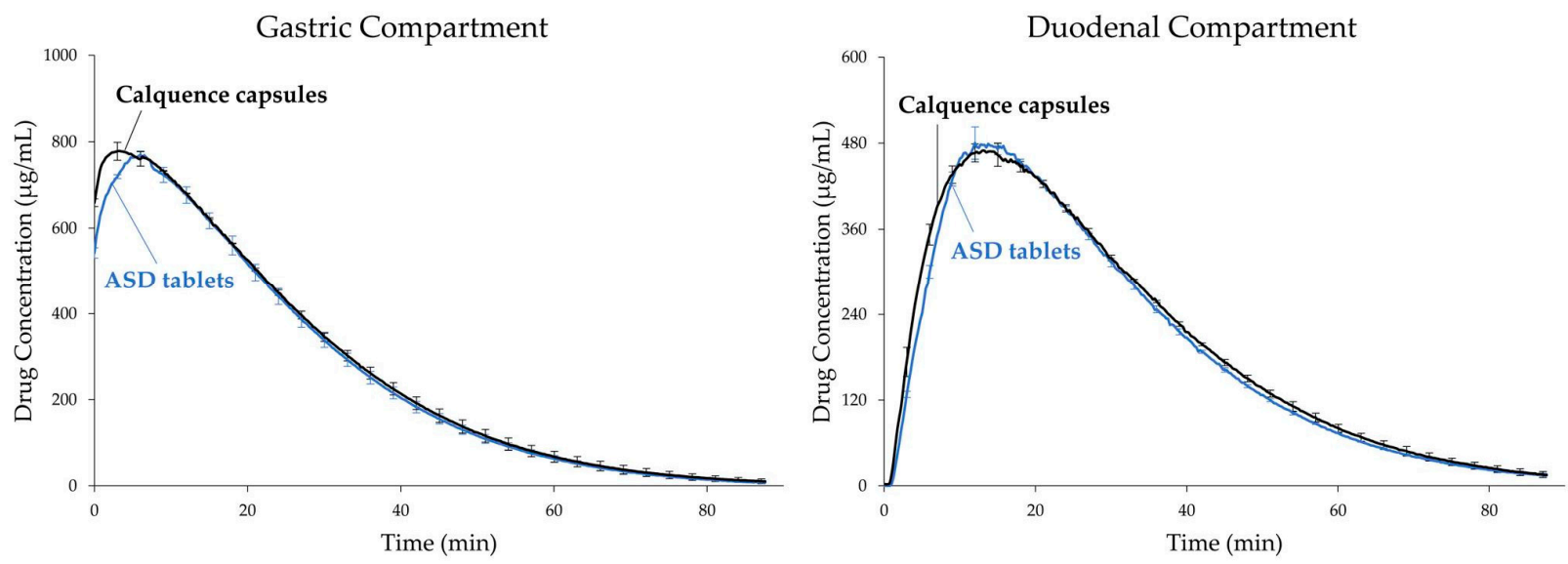

Figure 2. Dissolution profiles of acalabrutinib ASD tablets and Calquence capsules in CTD apparatus, using pH 2 gastric conditions to simulate fasted dogs treated with pentagastrin $(n=2)$. 
The dissolution profiles from the CTD apparatus using $1 \times 10^{-6} \mathrm{~N} \mathrm{HCl}(\mathrm{pH}$ 6) as the gastric medium are shown in Figure 3. In contrast to the $\mathrm{pH} 2$ results, the ASD tablet outperformed the Calquence capsule in conditions that simulated fasted dogs treated with ARAs such as famotidine. The crystalline solubility of acalabrutinib is orders of magnitude lower at $\mathrm{pH} 6$ than at $\mathrm{pH}$ 2. As such, the crystalline drug in the Calquence capsules is solubility-limited in the gastric compartment and does not supersaturate to the same extent when transferred to the duodenal compartment. In contrast, the ASD supersaturates in both the gastric and duodenal compartments, resulting in a 3.4-fold calculated enhancement in duodenal AUC for the ASD tablet relative to the Calquence capsules, as shown in Table 5.
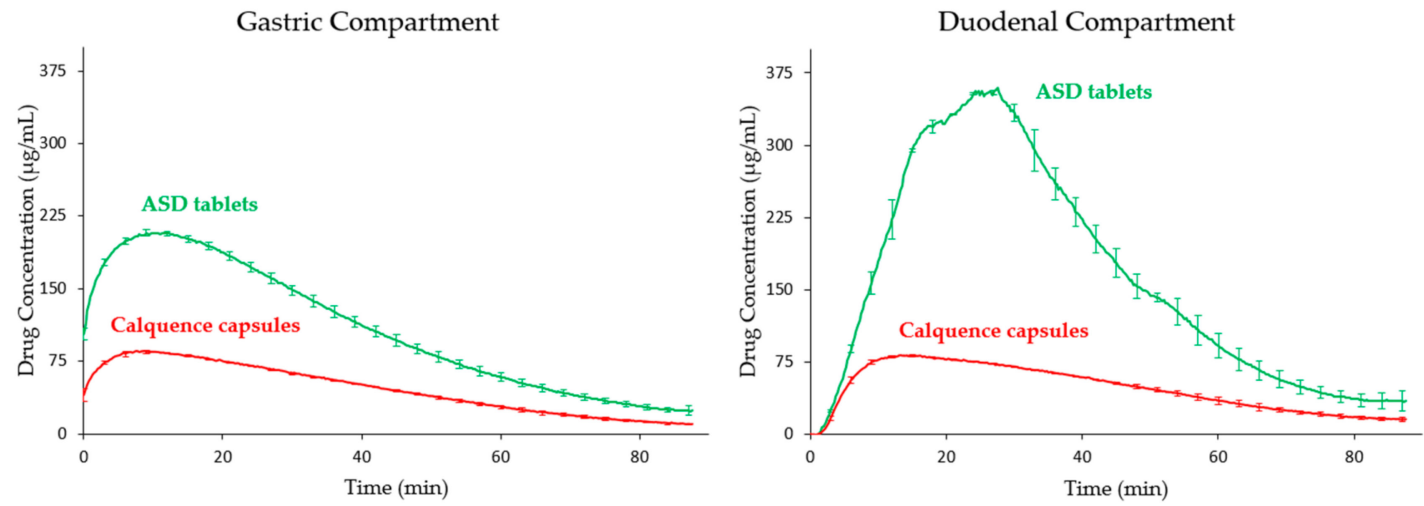

Figure 3. Dissolution profiles of acalabrutinib ASD tablets and Calquence capsules in the CTD apparatus under $\mathrm{pH} 6$ gastric conditions to simulate fasted dogs treated with famotidine (ARAs) $(n=2)$.

Table 5. Calculated in vitro AUC in the duodenal compartment during CTD testing of ASD tablets and Calquence capsules.

\begin{tabular}{|c|c|c|}
\hline $\begin{array}{l}\text { Test Article with } \\
\text { Simulated Pretreatment }\end{array}$ & $\begin{array}{c}\text { Average In Vitro } \\
\text { Duodenal AUC } \\
(\mu \mathrm{g}-\mathrm{min} / \mathrm{mL})\end{array}$ & $\begin{array}{c}\text { In Vitro AUC Ratio } \\
\text { (Famotidine/ } \\
\text { Pentagastrin) }\end{array}$ \\
\hline $\begin{array}{l}\text { ASD tablet, pentagastrin } \\
\text { (pH } 2 \text { stomach) }\end{array}$ & 16,946 & 0.83 \\
\hline $\begin{array}{l}\text { ASD tablet, famotidine } \\
\text { (pH } 6 \text { stomach) }\end{array}$ & 14,102 & - \\
\hline $\begin{array}{l}\text { Calquence, pentagastrin } \\
\qquad(\mathrm{pH} 2 \text { stomach) }\end{array}$ & 17,617 & 0.24 \\
\hline $\begin{array}{l}\text { Calquence, famotidine } \\
\text { (pH } 6 \text { stomach) }\end{array}$ & 4173 & - \\
\hline
\end{tabular}

\subsection{PK Study}

ASD tablets and Calquence capsules were dosed to dogs pretreated with pentagastrin or famotidine. Profiles for blood plasma concentration versus time for each formulation treatment from 0 to $12 \mathrm{~h}$ are plotted in Figure 4, with tabulated noncompartmental PK results in Table 6. Profiles of blood plasma drug concentration versus time from 0 to $24 \mathrm{~h}$ and additional noncompartmental PK results can be found in Appendix A.6. The performance of the Calquence capsules and ASD tablets was similar after pentagastrin pretreatment. This result is in line with expectations prior to study initiation and supports historical performance data in dogs and humans, where acalabrutinib is well absorbed when administered to subjects with low stomach $\mathrm{pH}[2,6]$.

For the famotidine pretreatment condition, the ASD tablet achieved a 2.4-fold higher AUC than the Calquence capsules, as well as approximately $93 \%$ of the AUC observed for the pentagastrin-treated dogs, overcoming the impact of stomach $\mathrm{pH}$. As expected, the performance of the Calquence capsules suffered at high stomach $\mathrm{pH}$, resulting in roughly a 3-fold decrease in $\mathrm{AUC}_{0 \text {-inf }}$ compared to the pentagastrin-treated dogs. Again, this is in line with expectations based on historical performance data for Calquence dosed 


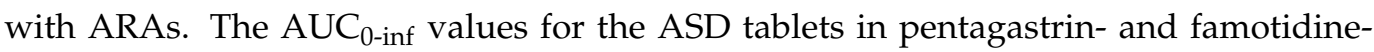
treated dogs were statistically equivalent to each other, and to that of the Calquence capsules for pentagastrin-treated dogs. However, the $\mathrm{AUC}_{0 \text {-inf }}$ values for the ASD tablet in pentagastrin- and famotidine-treated dogs were statistically higher than the $\mathrm{AUC}_{0 \text {-inf }}$ values for Calquence capsules in famotidine-treated dogs.

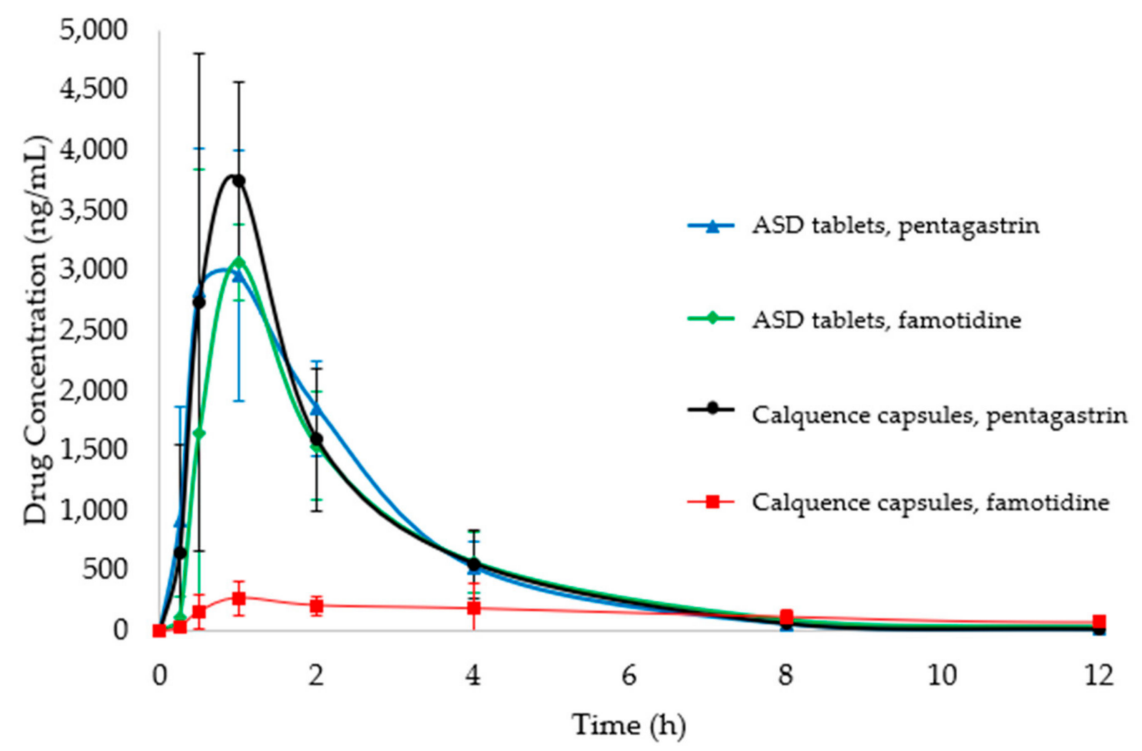

Figure 4. Profiles for blood plasma concentration versus time from 0 to $12 \mathrm{~h}$ measured in beagle dogs for ASD tablets and Calquence capsules $(n=6)$.

Table 6. Noncompartmental PK results from the acalabrutinib beagle dog study. Data are reported as the mean with the standard deviation in parentheses.

\begin{tabular}{|c|c|c|c|c|}
\hline Test Article, Pretreatment & $\begin{array}{l}\text { ASD Tablet, } \\
\text { Pentagastrin }\end{array}$ & $\begin{array}{c}\text { ASD } \\
\text { Tablet, } \\
\text { Famotidine }\end{array}$ & $\begin{array}{c}\text { Calquence } \\
\text { Capsule, } \\
\text { Pentagastrin }\end{array}$ & $\begin{array}{c}\text { Calquence } \\
\text { Capsule, } \\
\text { Famotidine }\end{array}$ \\
\hline $\mathrm{AUC}_{0-\mathrm{inf}}(\mathrm{ng}-\mathrm{h} / \mathrm{mL})$ & $8161(1364)^{a}$ & $7579(1423)^{a}$ & $8365(1201)$ & $3112(1415)^{b}$ \\
\hline $\mathrm{C}_{\max }(\mathrm{ng} / \mathrm{mL})$ & $3332(769)$ & $3443(996)$ & $4480(516)$ & $355(121)$ \\
\hline $\mathrm{T}_{\max }(\mathrm{h})$ & $0.9(0.5)$ & $0.9(0.2)$ & $0.8(0.2)$ & $1.6(1.2)$ \\
\hline AUC ratio compared to Calquence capsule, pentagastrin & 0.98 & 0.91 & 1.00 & 0.37 \\
\hline
\end{tabular}

a Statistically equivalent to Calquence capsule, pentagastrin $(p>0.05) .{ }^{\mathrm{b}}$ Statistically different from Calquence capsule, pentagastrin $(p<0.05)$.

\section{Discussion}

\subsection{ASDs for Improving Low-Solubility, Weakly Basic Drugs}

ASD dosage forms are attractive for enhancing the oral exposure of poorly soluble (e.g., BCS Class 2 and 4) drugs. The ASD tablets in this study boost AUC values 2.4fold compared to that of Calquence capsules in beagle dogs at high gastric $\mathrm{pH}$ levels. Based on this result, ASD tablets are a promising alternative to Calquence capsules for improving patient compliance and efficacy [5]. Currently, patients are instructed to avoid co-administration with PPIs and to stagger dosing with $\mathrm{H}_{2}$ RAs and antacids, so these ASD tablets present the potential for co-administration with all types of ARAs [1]. Furthermore, these ASD tablets are $60 \%$ smaller than Calquence capsules at the same unit dosage strength, which should make them easier for patients to swallow [24,25]. While the ASD tablets were manufactured with a round, convex shape for this dog study, the size reduction is expected to translate to other tablet shapes (e.g., oblong) that may further facilitate swallowability in humans [24].

The results of this study are generally applicable to other small-molecule protein kinase inhibitors besides acalabrutinib, as well as weakly basic drugs in general. Several weakly basic, oral oncologic drugs on the market have shown evidence of decreased 
absorption as a result of high gastric $\mathrm{pH}$ when taken with ARAs [26,27]. Weakly basic drugs made up 78\% of new molecular entities approved between 2003 and 2013 that showed a clinical DDI with ARAs [4]. Since small-molecule protein kinase inhibitors are prevalent in pharmaceutical pipelines and many are poorly soluble, ASD dosage forms have the potential to enable effective delivery and improve the experience of many cancer patients [28-31]. In addition to removing the ARA effect as highlighted in this study, ASD dosage forms can also mitigate food effects, decrease plasma variability and reduce dose $[30,32]$.

\subsection{In Vitro Versus In Vivo Performance}

The in vitro CTD methodology forecast relative in vivo performance between the ASD tablet and Calquence capsules a priori to the dog study. As shown in Figure 5, the in vivo AUC values of ASD tablets relative to that of Calquence capsules in the pentagastrin pretreatment phase showed the same rank-ordering as in vitro duodenal AUC values relative to those of Calquence capsules at $\mathrm{pH} 2$ (the initial gastric $\mathrm{pH}$ condition).

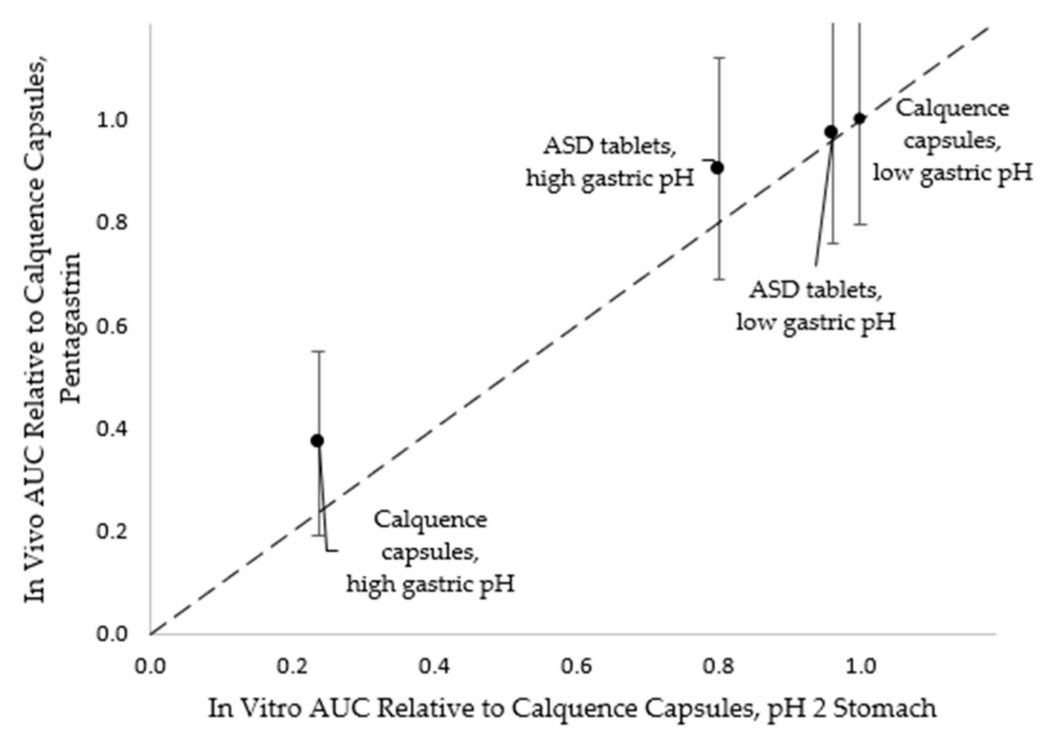

Figure 5. AUC values relative to those of Calquence capsules (pentagastrin pretreatment) in vivo versus duodenal AUC values relative to those of Calquence capsules ( $\mathrm{pH} 2$ initial gastric $\mathrm{pH}$ ) in vitro. Relative AUC is calculated using average AUC. Error bars represent fractional uncertainties, where uncertainty in AUC is the standard deviation. Dashed line $=1: 1$ correlation line.

On average, the ASD tablets performed somewhat better in vivo than they did in vitro relative to the Calquence capsules at low initial gastric $\mathrm{pH}$. This result is not surprising, because high-permeability drugs such as acalabrutinib often perform better in vivo than in vitro using dissolution test apparatuses that lack an absorption compartment $[33,34]$. Coupling in vitro testing with in silico modeling is a useful strategy for capturing the sensitivity of formulations to the multitude of important physiological variables $[35,36]$. Nonetheless, in this study, the CTD methodology proved useful in forecasting the in vivo performance of the ASD tablets and Calquence capsules.

\subsection{Dog Model for Studying ARA Effect}

In this study, a dog model was chosen to demonstrate the ability of an ASD dosage form to mitigate the acalabrutinib ARA effect. Beagle dogs are a common preclinical species and surrogate for humans due to their ability to swallow intact dosage forms and the relative ease in maintaining the animals. Although beagle dogs can be useful surrogates for humans, several differences exist between human and beagle dog physiology, including gastric $\mathrm{pH}[23,37,38]$. 
It is common practice to modulate gastric $\mathrm{pH}$ in dogs when evaluating oral drug product performance. Pretreatment with intramuscular pentagastrin or oral famotidine has provided gastric $\mathrm{pH}$ values in beagle dogs that were more consistent and stable than those of dogs that had not been pretreated-in the range of $\mathrm{pH} 1-2$ (for pentagastrin) or $\mathrm{pH} 7$ (for famotidine) $[17,18]$. These findings make intramuscular pentagastrin and oral famotidine pretreatments useful for studying the impact of a wide range in gastric $\mathrm{pH}$ on weakly basic drugs, as was done in this study [17,18,39-41].

Famotidine represents a worst-case scenario for weakly basic drugs since a $\mathrm{pH}$ of 7 falls at the high end of the $\mathrm{pH}$ range, where drug solubility is lowest. Measured gastric $\mathrm{pH}$ in humans after taking ARAs can range from approximately $\mathrm{pH} 3$ to 7 depending upon type of ARA, dose, duration of treatment, and individual response [42-44]. Therefore, the fact that the difference in AUC of the ASD tablet was only $7 \%$ over such a wide $\mathrm{pH}$ range (i.e., $\sim 1$ to 7), suggests low $\mathrm{pH}$ sensitivity and high-performance robustness for different ARA treatments. Further, it suggests high robustness of the ASD tablet to the natural $\mathrm{pH}$ variations that can be found even in patients who are not taking ARAs [8].

In attempting to use the current dog study results to forecast the utility of ASDs for overcoming $\mathrm{pH}$ effects in humans, it should be noted that acalabrutinib metabolism differs substantially between humans and dogs. In humans, approximately $50 \%$ of acalabrutinib is metabolized by CYP3A4 in the gut and 50\% is metabolized by first-pass liver extraction [2]. In contrast, in dogs, acalabrutinib undergoes less-extensive metabolism upon first pass through the gut and liver, with reports of bioavailability in the $70 \%$ to $80 \%$ range at the human prescribed dose $(100 \mathrm{mg})[2,45]$. In humans, lower solubility at high gastric $\mathrm{pH}$ purportedly reduces absorption across the GI membrane and increases the extent of metabolized drug, whereas in dogs, the lower solubility at higher $\mathrm{pH}$ is expected to primarily reduce absorption [2]. Despite these metabolism differences, in both dogs and humans, the ASD tablet increases dissolved drug concentrations at elevated gastric $\mathrm{pH}$ levels. Therefore, success in dogs suggests that the ASD tablets will also overcome the ARA effect in humans.

\section{Conclusions}

This study demonstrates that ASD tablets are an effective enabling technology for overcoming reduction in AUC of the weakly basic drug acalabrutinib when co-administered with a gastric ARA. In beagle dogs, ASD tablets achieved similar AUC values at low and high gastric $\mathrm{pH}$ conditions and outperformed Calquence capsules 2.4-fold at high gastric $\mathrm{pH}$. Relative formulation performance was successfully forecast using a multicompartment in vitro CTD apparatus.

The ASD was easy to manufacture at high yield on laboratory-scale spray-drying equipment and the resulting ASD tablets were $60 \%$ smaller than Calquence capsules. The ASD had good physical stability and the ASD and ASD tablet showed good chemical stability when stored refrigerated or at room temperature with a desiccant. An ASD dosage form represents a useful strategy for improving patient compliance and efficacy of acalabrutinib. This strategy could be extended to other small-molecule drug products and problem statements requiring bioavailability enhancement to drive improved in vivo performance.

Author Contributions: Conceptualization, D.M.M., A.M.S., N.B., M.M.M., and D.T.V.; methodology, D.M.M., A.M.S., J.A.R., M.S.A., C.D.C., and M.M.M.; formal analysis, D.M.M., A.M.S., and J.A.R.; investigation, J.A.R., N.B., M.S.A., and A.S.; data curation, D.M.M., A.M.S., and J.A.R.; writing—original draft preparation, D.M.M., A.M.S., and J.A.R.; writing-review and editing, D.M.M., A.M.S., J.A.R., M.S.A., and M.M.M.; visualization, D.M.M., A.M.S., and J.A.R.; supervision, D.M.M. and D.T.V.; project administration, D.M.M. All authors have read and agreed to the published version of the manuscript.

Funding: This research received no external funding. 
Institutional Review Board Statement: The dog study was performed at Covance Laboratories. All procedures were in compliance with the Animal Welfare Act Regulations (9 CFR 3) as mandated by Animal and Plant Health Inspection Service, United States Department of Agriculture.

Informed Consent Statement: Not applicable.

Data Availability Statement: The data in this study in the form of Microsoft Excel worksheets are available from the corresponding author upon request.

Acknowledgments: We would like to thank Covance Laboratories (Madison, WI, USA) for conducting the in vivo study. We would like to thank Henny Zijlstra for identifying the Calquence ARA-effect problem statement. We would also like to thank Dwayne T. Friesen for his scientific advice in developing the in vivo study and Terry Podoll for his correspondence about acalabrutinib metabolism in beagle dogs. We would like to thank Jonathan Cape for his scientific advice on the chemical stability analysis, and we would like to thank Lauren Switala and Kimberly Shepard for assistance with analytical characterization. We would also like to thank Ann Malkin for her review and editing of the manuscript. No financial support or funding was provided for this work.

Conflicts of Interest: The authors declare no conflict of interest.

\section{Appendix A}

The following is available in the Appendix A.1 API, ASD and ASD tablet characterization methods, Appendix A.2 ASD tablet manufacturing methods, Appendix A.3 physical and chemical stability methods, Appendix A.4 ASD and API characterization results, Appendix A.5 physical and chemical stability results and discussion, and Appendix A.6 PK study results.

Appendix A.1. Active Pharmaceutical Ingredient (API), Amorphous Solid Dispersion (ASD) and ASD Tablet Characterization Methods

Appendix A.1.1. Modulated Differential Scanning Calorimetry (mDSC)

API was analyzed to determine the glass-transition temperature $\left(T_{g}\right)$ using a Mettler Toledo DSC 3+ instrument (Mettler Toledo, LLC, Columbus, OH, USA). Samples were prepared as loose powder, loaded into a hermetically sealed pan perforated just before scanning. The instrument was run in alternating DSC mode at a scan rate of $2.5^{\circ} \mathrm{C} / \mathrm{min}$, modulation of $\pm 1.5^{\circ} \mathrm{C} / \mathrm{min}$, and scan range of $25-160{ }^{\circ} \mathrm{C}(n=2)$.

A 50/50 ASD was spray dried as described in the text using acalabrutinib and the HF grade of hydroxypropyl methylcellulose acetate succinate (HPMCAS-HF) (Aqoat). The ASDs were analyzed to confirm that they were homogeneous (as evidenced by a single $T_{g}$ ) using a TA Instruments Q2000 mDSC instrument (TA Instruments-Waters LLC, New Castle, DE, USA). Samples were prepared as loose powder, loaded into a $T_{\text {zero }}$ nonhermetically sealed pan (TA Instruments). The instrument was run in modulated mode at a scan rate of $2.5^{\circ} \mathrm{C} / \mathrm{min}$, modulation of $\pm 1.5^{\circ} \mathrm{C} / \mathrm{min}$, and scan range of $0-160{ }^{\circ} \mathrm{C}(n=3)$. As-received HPMCAS-HF was also analyzed using $\mathrm{mDSC}$ as a reference using the same method used for the $\operatorname{ASD}(n=2)$.

\section{Appendix A.1.2. Powder X-ray Diffraction (PXRD)}

ASD samples were analyzed using PXRD to confirm they were amorphous, as evidenced by the lack of sharp Bragg diffraction peaks in the X-ray pattern, using a Rigaku MiniFlex600 X-ray diffractometer (Rigaku, The Woodlands, TX, USA) equipped with a $\mathrm{Cu}-\mathrm{K} \alpha$ source. The scan rate was set to $2.5^{\circ} / \mathrm{min}$ with a $0.02^{\circ}$ step size from $3^{\circ}$ to $40^{\circ}$ on the $2 \Theta$ scale.

Appendix A.1.3. Scanning Electron Micrography (SEM)

As-received API and ASD samples were imaged using a Hitachi SU3500 scanning electron microscope (Hitachi High Technologies America Inc., Schaumburg, IL, USA) to assess morphology and confirm the absence of crystals. Samples were spread onto a post 
using double-sided tape and sputter-coated for 8 minutes at $8 \mathrm{~V}$ and $20 \mathrm{~mA}$ using an Anatech Hummer 6.2 sputter coater (Anatech USA, Hayward, CA, USA).

Appendix A.1.4. Reverse-Phase High-Performance Liquid Chromatography (RP-HPLC)

ASD and ASD tablet samples were analyzed for total related substances using RPHPLC using a Waters XBridge C $8(150 \times 3 \mathrm{~mm}, 3.5 \mu \mathrm{m}$ pores) column (Waters Corporation, Milford, MO, USA) at a temperature of $40{ }^{\circ} \mathrm{C}$. Mobile phase was pumped into the column at a flow rate of $0.7 \mathrm{~mL} / \mathrm{min}$ using a gradient method. $10 \mathrm{mM}$ ammonium acetate was used as mobile phase $\mathrm{A}$ and methanol was used as mobile phase $\mathrm{B}$ supplied according to the following sequence: $0 \mathrm{~min}: 20 \% \mathrm{~B}, 30 \mathrm{~min}: 70 \% \mathrm{~B}, 40 \mathrm{~min}: 70 \% \mathrm{~B}, 41 \mathrm{~min}: 20 \% \mathrm{~B}, 45$. Samples were diluted with $8 / 2(v / v)$ methanol/water and injection volume was $5 \mu \mathrm{L}$. The sample tray was held at uncontrolled room temperature. Analysis wavelength was $230 \mathrm{~nm}$ and $4 \mathrm{~nm}$ bandwidth.

Appendix A.1.5. RP-HPLC-Mass Spectrometry (MS)

RP-HPLC-MS was performed as a first step in identifying acalabrutinib degradation products using a Sciex Qtrap-4000 triple quadrupole mass spectrometer (Sciex, Framingham, MA, USA) interfaced with an Agilent 1200 HPLC (Agilent Technologies, Santa Clara, CA, USA). The RP-HPLC method was modified from the RP-HPLC method described above to adapt the method to the lower pressure limit of the 1100 Agilent HPLC instrument. A Waters XBridge C8 (150 3 mm, $3.5 \mu \mathrm{m}$ pores) column (Waters Corporation, Milford, MO, USA) was used for the separation at a column oven temperature of $45^{\circ} \mathrm{C}$. Mobile phase was pumped into the column at a flow rate of $0.5 \mathrm{~mL} / \mathrm{min}$ using a gradient method. $10 \mathrm{mM}$ ammonium acetate was used as mobile phase $\mathrm{A}$ and methanol was used as mobile phase B supplied according to the following sequence: $0 \mathrm{~min}: 20 \% \mathrm{~B}, 30 \mathrm{~min}: 70 \% \mathrm{~B}, 40 \mathrm{~min}$ : $70 \%$ B, $41 \mathrm{~min}: 20 \%$ B, 45. Samples were diluted with $8 / 2(v / v)$ methanol/water and injection volume was $5 \mu \mathrm{L}$. The sample tray was held at uncontrolled room temperature. The eluent was first passed through the UV detector prior to entering the MS. The analysis wavelength was $230 \mathrm{~nm}$ and $4 \mathrm{~nm}$ bandwidth. MS parameters were as follows: Positive mode ionization, $3500 \mathrm{~V}$ ESI voltage, $250{ }^{\circ} \mathrm{C}$ heater temperature, $12 \mathrm{psi}$ gas source $1,15 \mathrm{psi}$ gas source 2, $60 \mathrm{~V}$ declustering potential, $10 \mathrm{~V}$ exit potential. Q1 MS scans were conducted from 100 to $1000 \mathrm{~m} / \mathrm{z}$ with a $500 \mathrm{~ms}$ cycle time.

\section{Appendix A.2. ASD Tablet Manufacturing Methods}

ASD tablets were made using a small-scale, semi-manual manufacturing process. ASD and intragranular excipients (see Table 2 in main text) were passed through a \#20 mesh screen. The ASD and all intragranular excipients excluding magnesium stearate were blended in a Turbula blender (Glen Mills Inc., Clifton, NJ, USA) for $15 \mathrm{~min}$ at $32 \mathrm{rpm}$. Magnesium stearate was added to the blender and the mixture was blended for $4 \mathrm{~min}$ at $32 \mathrm{rpm}$. The intragranular blend was compressed into slugs using a Manesty F3 singlestation tablet press (Manesty Ltd., Knowsley, Great Britain) equipped with half-inch flatfaced tooling. The compression pressure was adjusted to achieve tensile strengths in the range of 0.5-0.7 MPa. Tensile strength was calculated using Equation (A1), where TS is tensile strength, $\mathrm{F}$ is breaking force, $\mathrm{D}$ is tablet diameter, and $\mathrm{H}$ is tablet thickness.

$$
\mathrm{TS}=\frac{2 \mathrm{~F}}{\pi \mathrm{DH}}
$$

Breaking force was determined using a Schleuniger hardness tester (Sotax, Westborough, MA, USA).

Slugs were milled using a 1Zpresso Pro coffee grinder (1Zpresso, New Taipei City, Taiwan) at a setting of 4.5. The extragranular Cab-O-Sil was passed through a \#20 mesh screen and added to a Turbula blender together with Ac-Di-Sol and the intragranular blend and blended for 15 minutes at $32 \mathrm{rpm}$. The magnesium stearate was screened through a \#20 mesh screen and added to the Turbula blender for an additional $4 \mathrm{~min}$ of blending. The 
final blend was then compressed into tablets of a target tensile strength of $2 \mathrm{MPa}$ using the Manesty F3 press equipped with $11 \mathrm{~mm}$ standard round concave (SRC) tooling.

\section{Appendix A.3. Physical and Chemical Stability Methods}

The ASD was stored at $40{ }^{\circ} \mathrm{C} / 75 \%$ relative humidity (RH) to assess physical and chemical stability when stored under accelerated conditions. Approximately $100 \mathrm{mg}$ of ASD was placed in a single $4 \mathrm{~mL}$ glass vial, with enough glass vials prepared for each storage condition, timepoint and replicate. Each vial was covered with perforated aluminum foil and transferred to a temperature/humidity-controlled oven (Model ES2000, Environmental Specialties International lnc., Baton Rouge, LA, USA) at $40{ }^{\circ} \mathrm{C} / 75 \% \mathrm{RH}$ and allowed to stand undisturbed for 4,12, and 24 weeks. At each timepoint, samples were removed from the oven and transferred to a vacuum desiccator for up to $18 \mathrm{~h}$ to remove water. After drying, the samples were removed from the vacuum desiccator and stored at $5 \pm 3{ }^{\circ} \mathrm{C}$. Initial ASD samples and aged ASDs were analyzed for crystallinity using SEM and PXRD, thermal properties using mDSC (in triplicate) and total related substances using RP-HPLC (duplicate analysis).

Additional ASD samples were stored at ambient and refrigerated conditions to assess the chemical stability upon storage at nonaccelerated conditions. The storage conditions are detailed in Table A1. Approximately $100 \mathrm{mg}$ of ASD was placed in a single $4 \mathrm{~mL}$ glass vial, with enough glass vials prepared for each storage condition, timepoint and replicate. A subset of vials was placed in sealed $40 \mathrm{cc}$ high-density polyethylene (HDPE) bottles with and without $1 \mathrm{~g}$ of desiccant. These vials were subsequently stored at $5{ }^{\circ} \mathrm{C}$ for 2 , 5 , and 12 weeks. A second subset of vials was placed in sealed $40 \mathrm{cc}$ HDPE bottles with desiccant as well as $40 \mathrm{cc}$ HDPE bottles with perforated aluminum seals (without desiccant). These vials were subsequently transferred to a temperature- and humidity-controlled oven held at $25^{\circ} \mathrm{C} / 60 \% \mathrm{RH}$ and allowed to stand undisturbed for 2, 5, and 12 weeks. At each timepoint, samples were removed from storage and transferred to a vacuum desiccator for up to 18 hours to remove water. After drying, the samples were removed from the vacuum desiccator and stored at $5{ }^{\circ} \mathrm{C}$. Initial and aged ASD samples were analyzed for total related substances using RP-HPLC (duplicate analysis).

ASD tablets were stored at ambient and refrigerated conditions to assess chemical stability (See Table A1). A subset of tablets were placed in sealed $40 \mathrm{cc}$ HDPE bottles with and without $1 \mathrm{~g}$ of desiccant. These bottles were subsequently stored at $5{ }^{\circ} \mathrm{C} \pm 3{ }^{\circ} \mathrm{C}$ for 2,5 , and 12 weeks. A second subset of tablets were placed in sealed $40 \mathrm{cc}$ HDPE bottles with desiccant as well as $40 \mathrm{cc}$ HDPE bottles with perforated aluminum seals (without desiccant). These bottles were then transferred to a temperature- and humidity-controlled oven held at $25^{\circ} \mathrm{C} / 60 \% \mathrm{RH}$ and allowed to stand undisturbed for 2, 5, and 12 weeks. At each timepoint, samples were removed from storage and stored at $5{ }^{\circ} \mathrm{C}$. Initial and aged tablets were analyzed for total related substances using RP-HPLC.

Table A1. Storage conditions for the evaluation of ASD and ASD tablet stability. Checkmarks indicate the conditions that were tested for each sample.

\begin{tabular}{|c|c|c|c|c|}
\hline No. & Storage Conditions & $\begin{array}{c}\text { ASD } \\
\text { Physical Stability }\end{array}$ & $\begin{array}{c}\text { ASD } \\
\text { Chemical Stability }\end{array}$ & $\begin{array}{c}\text { ASD Tablet Chemical } \\
\text { Stability }\end{array}$ \\
\hline 1 & $\begin{array}{c}5{ }^{\circ} \mathrm{C} / \text { sealed with } \\
\text { desiccant }\end{array}$ & & $\checkmark$ & $\boldsymbol{v}$ \\
\hline 2 & $5{ }^{\circ} \mathrm{C} /$ sealed & & $\checkmark$ & $\checkmark$ \\
\hline 3 & $\begin{array}{c}25^{\circ} \mathrm{C} / 60 \% \mathrm{RH} / \text { sealed } \\
\text { with desiccant }\end{array}$ & & $\boldsymbol{v}$ & $\checkmark$ \\
\hline 4 & $\begin{array}{c}25{ }^{\circ} \mathrm{C} / 60 \% \mathrm{RH} / \text { open, } \\
\text { perforated seal }\end{array}$ & & $\boldsymbol{v}$ & $\boldsymbol{v}$ \\
\hline 5 & $\begin{array}{l}40{ }^{\circ} \mathrm{C} / 75 \% \mathrm{RH} / \text { open, } \\
\text { perforated seal }\end{array}$ & $\boldsymbol{V}$ & & \\
\hline
\end{tabular}




\section{Appendix A.4. ASD and API Characterization Results}

The ASD was confirmed to be a homogenous single-phase amorphous solid by PXRD, mDSC, and SEM. The PXRD diffraction patterns of the ASD showed no evidence of crystallinity, demonstrated by the absence of sharp diffraction peaks characteristic of pure crystalline acalabrutinib, as shown in Figure A1. SEM images showed typical SDD surface morphology with no evidence of surface crystals, as shown in Figure A2, panel (a). The mDSC thermograms showed a single, average dry $\mathrm{T}_{\mathrm{g}}$ of $115.6 \pm 0.3^{\circ} \mathrm{C}$, as shown in Figure A3. As-received API showed blade-like morphology, as shown in Figure A2, panel (b).

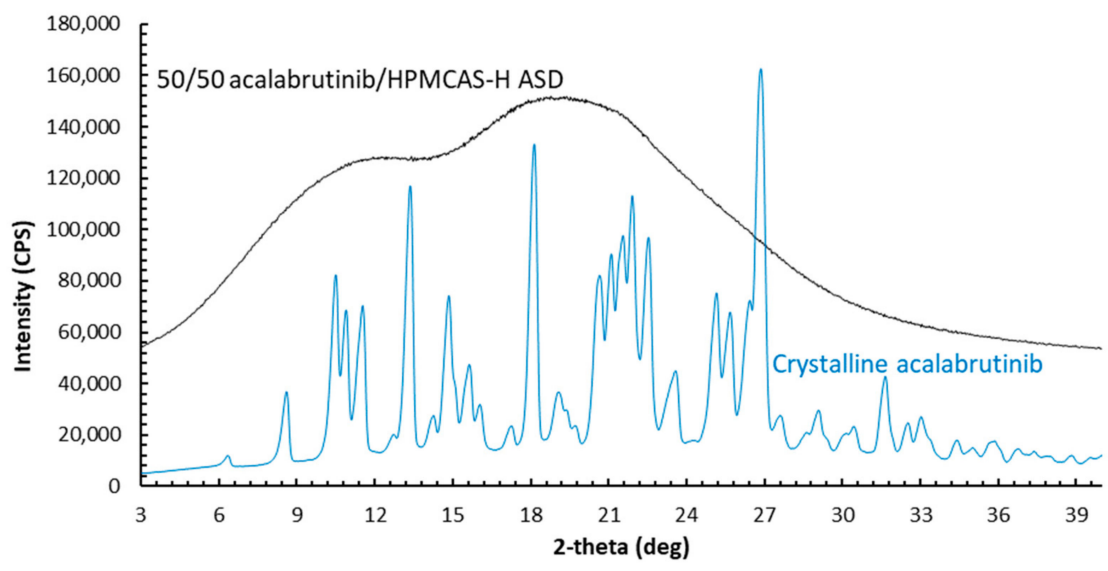

Figure A1. PXRD diffractograms for the ASD and crystalline drug.

(a)

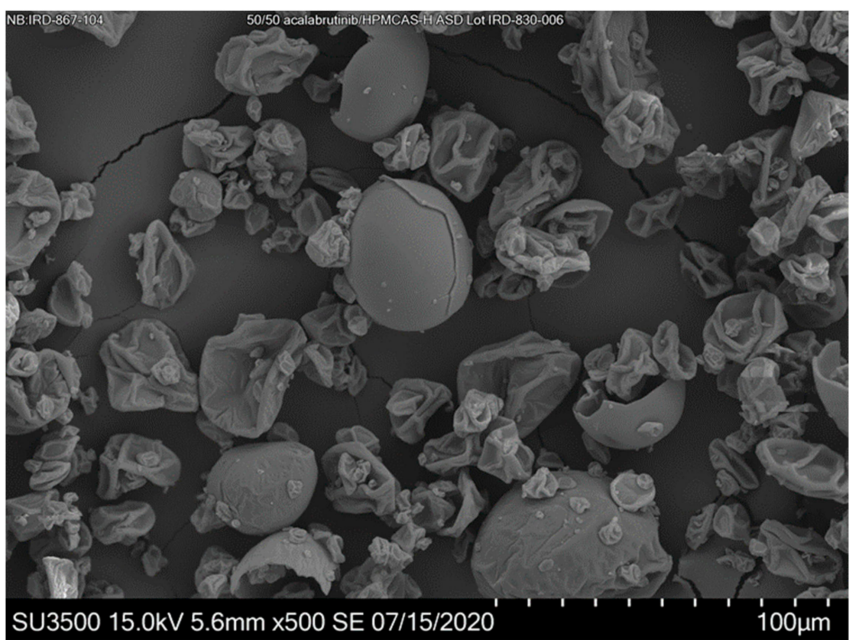

(b)

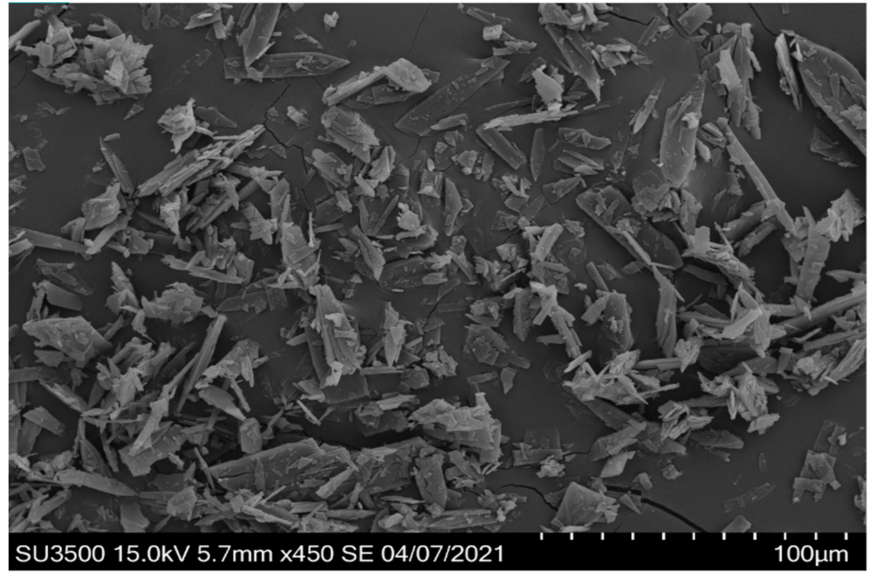

Figure A2. Panel (a): SEM micrograph of the ASD, panel (b); SEM micrograph of as-received acalabrutinib. 
(a)

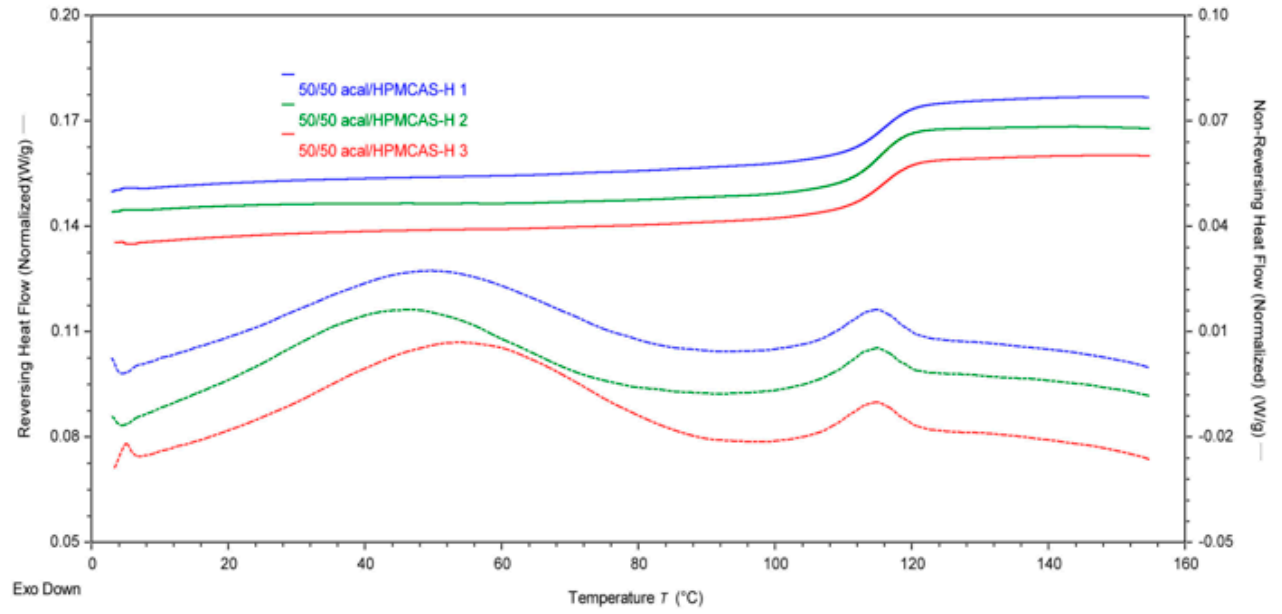

(b)

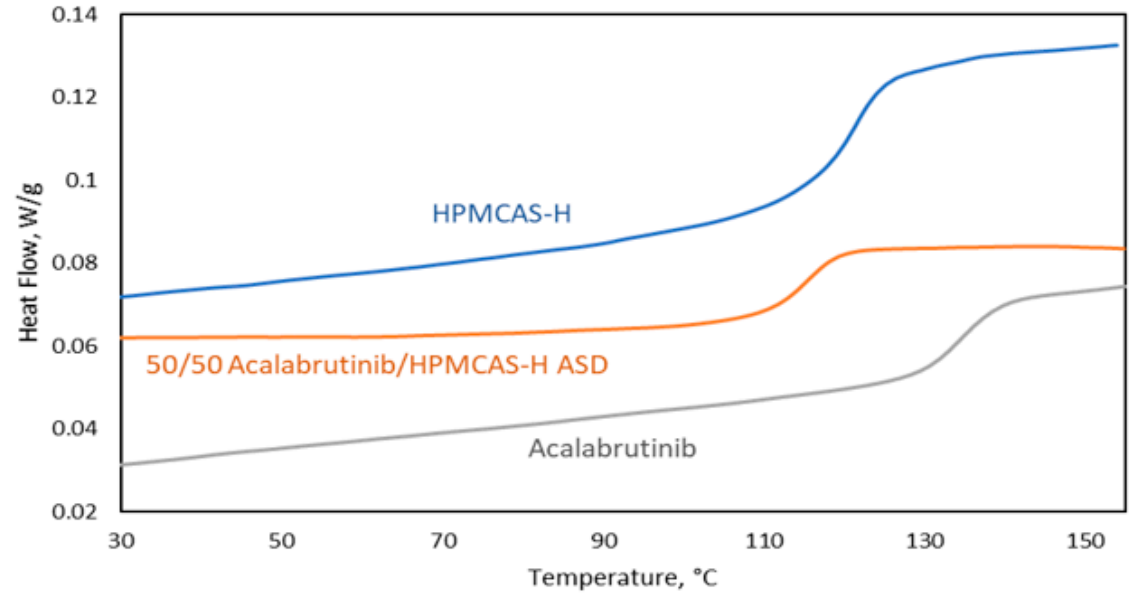

Figure A3. Panel (a): mDSC thermograms of the ASD samples, showing a single $\mathrm{T}_{\mathrm{g}}$ at $115.6{ }^{\circ} \mathrm{C}$. Panel (b): single replicate thermograms of ASD sample compared to acalabrutinib API $\left(\mathrm{T}_{\mathrm{g}}=133{ }^{\circ} \mathrm{C}\right)$ and HPMCAS-H $\left(\mathrm{T}_{\mathrm{g}}=121{ }^{\circ} \mathrm{C}\right)$ samples for reference.

\section{Appendix A.5. Physical and Chemical Stability Results and Discussion}

The ASD remained physically stable when stored at $40{ }^{\circ} \mathrm{C} / 75 \% \mathrm{RH}$ open for 6 months. Good physical stability was indicated by a lack of sharp diffraction peaks by PXRD (see Figure A4), a lack of particle fusion or other particle surface morphology changes by SEM micrography (see Figure A5, and a single $\mathrm{T}_{\mathrm{g}}$ by mDSC (see Figure A6) after aging at accelerated conditions.

Testing demonstrated the ASD and ASD tablets had good chemical stability after 12 weeks of storage at refrigerated conditions with and without desiccant, and at $25^{\circ} \mathrm{C} / 60 \%$ RH sealed with desiccant (see Tables A2 and A3). When refrigerated, both the ASD and ASD tablets showed no increase in impurities after 12 weeks of storage. When stored at $25{ }^{\circ} \mathrm{C} / 60 \% \mathrm{RH}$ sealed with desiccant for 12 weeks, the ASD showed no increase in impurities and the ASD tablets showed a small (6\%) increase in impurities. However, this increase was 4-fold lower than that observed for ASD tablets stored at $25^{\circ} \mathrm{C} / 60 \% \mathrm{RH} /$ open (with a perforated seal) without desiccant. Overall, the ASD and the ASD tablets showed a similar growth in impurities across all conditions.

Quantifying total impurities rather than identifying each impurity was the main focus of the chemical stability analysis. However, RP-HPLC-MS analysis provided a first step toward identifying impurities, as shown in Table A4. The degradant that increased the most upon storage was Ad4, with the proposed degradation pathway being alkyne hydration. Confidently identifying each degradant would require additional experimentation, which was outside the scope of this study. 


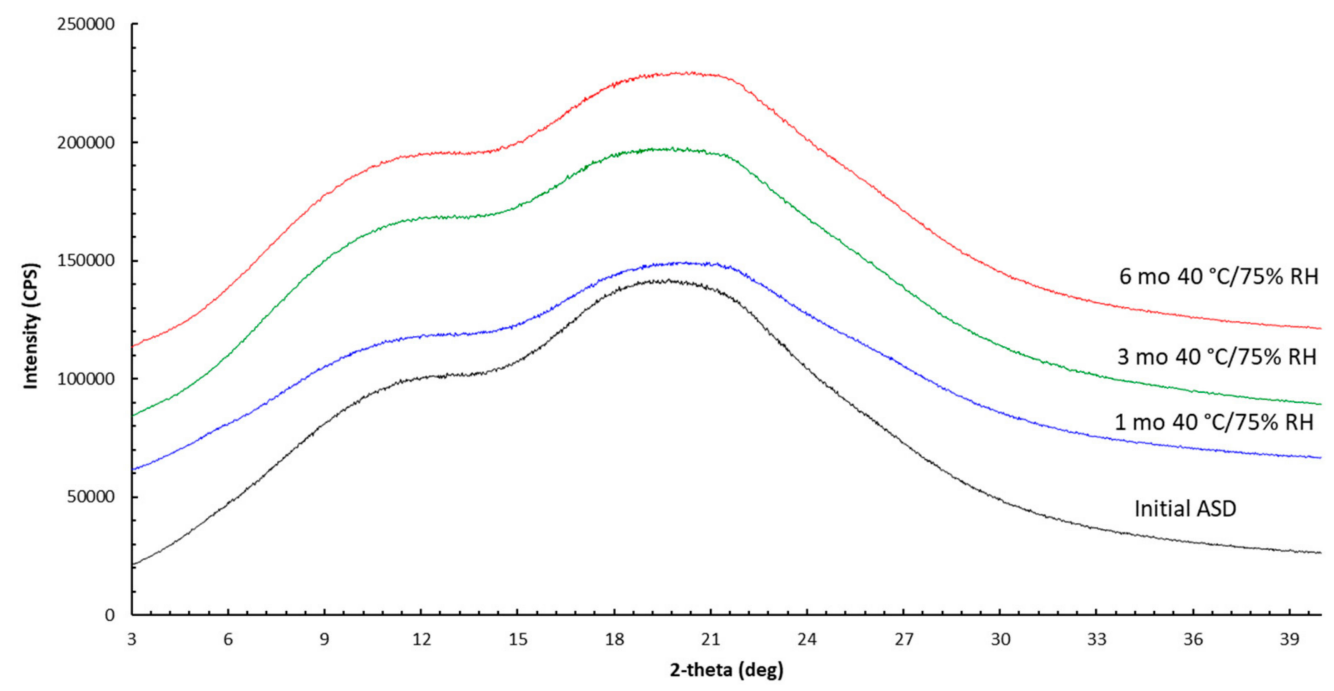

Figure A4. Diffractograms of ASD samples before and after storage at $40{ }^{\circ} \mathrm{C} / 75 \% \mathrm{RH}$ /open.

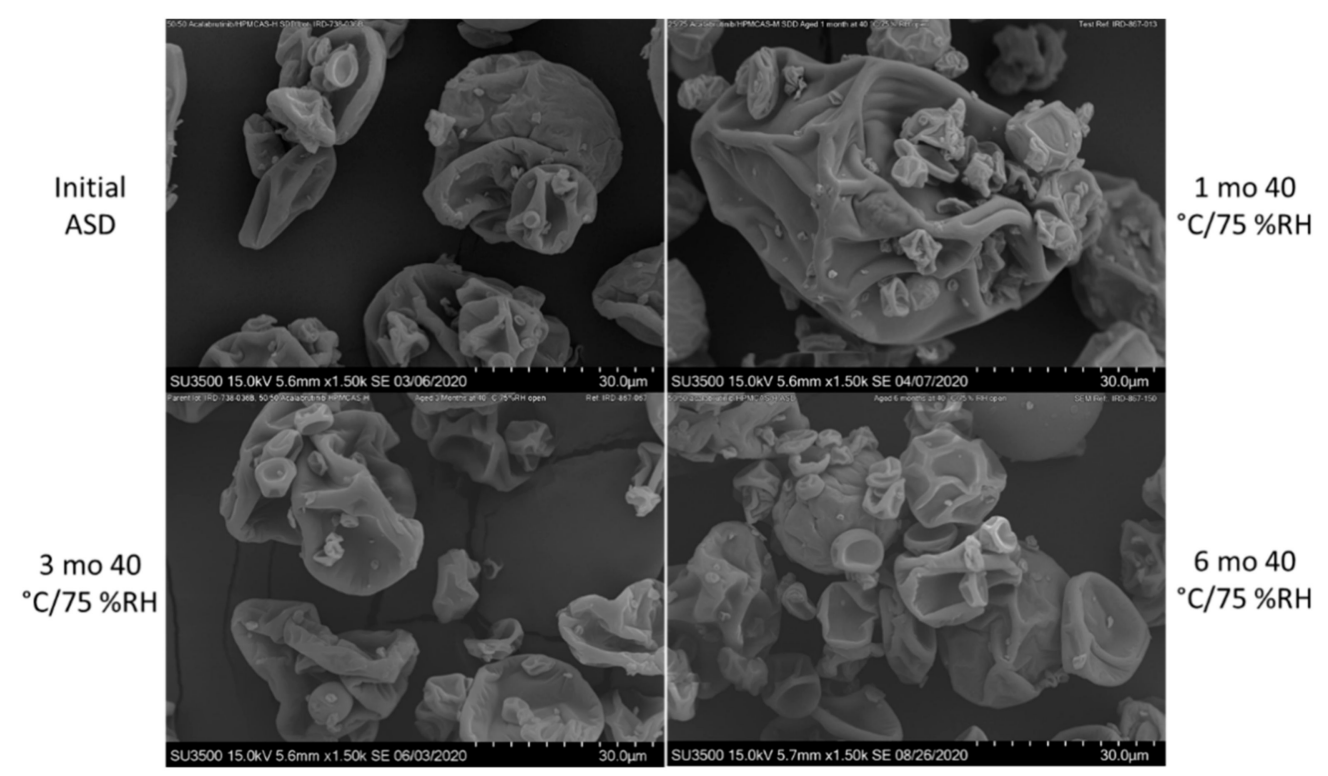

Figure A5. SEM micrographs of ASD samples before and after storage at $40{ }^{\circ} \mathrm{C} / 75 \% \mathrm{RH}$ /open.

Table A2. Total impurities of ASD and ASD tablets before and after storage for 12 weeks, as measured by HPLC.

\begin{tabular}{|c|c|c|c|c|c|c|}
\hline \multirow[b]{2}{*}{ Storage Condition } & \multicolumn{3}{|c|}{ ASD } & \multicolumn{3}{|c|}{ ASD Tablet } \\
\hline & $\begin{array}{c}\text { Initial } \\
\text { Impurities } \\
\text { (area\%) }\end{array}$ & $\begin{array}{l}\text { Impurities after } \\
12 \mathrm{wk}(\text { area } \%)\end{array}$ & $\begin{array}{l}\text { Change after } \\
12 \mathrm{wk}^{(\%)^{a}}\end{array}$ & $\begin{array}{c}\text { Initial } \\
\text { Impurities } \\
\text { (area\%) }\end{array}$ & $\begin{array}{l}\text { Impurities after } \\
12 \mathrm{wk}(\text { area } \%)\end{array}$ & $\begin{array}{l}\text { Change after } \\
12 \mathrm{wk}_{(\%)^{\mathrm{a}}}\end{array}$ \\
\hline $5^{\circ} \mathrm{C} /$ sealed with desiccant & $0.89 \pm 0.01$ & $0.85 \pm 0.00$ & -4.5 & $0.65 \pm 0.01$ & $0.63 \pm 0.01$ & -3.1 \\
\hline $5^{\circ} \mathrm{C} /$ sealed & $0.89 \pm 0.01$ & $0.89 \pm 0.01$ & 0.0 & $0.65 \pm 0.01$ & $0.63 \pm 0.01$ & -3.1 \\
\hline $\begin{array}{c}25^{\circ} \mathrm{C} / 60 \% \mathrm{RH} / \text { sealed with } \\
\text { desiccant }\end{array}$ & $0.89 \pm 0.01$ & $0.89 \pm 0.01$ & 0.0 & $0.65 \pm 0.01$ & $0.69 \pm 0.00$ & 6.2 \\
\hline $\begin{array}{c}25^{\circ} \mathrm{C} / 60 \% \mathrm{RH} / \text { open, } \\
\text { perforated seal }\end{array}$ & $0.89 \pm 0.01$ & $1.15 \pm 0.07$ & 29.2 & $0.65 \pm 0.01$ & $0.82 \pm 0.05$ & 26.2 \\
\hline $\begin{array}{l}40{ }^{\circ} \mathrm{C} / 75 \% \mathrm{RH} / \text { open, } \\
\text { perforated seal }\end{array}$ & $0.60^{b} \pm 0.01$ & $5.3 \pm 0.08$ & 783.3 & - & - & - \\
\hline
\end{tabular}

${ }^{\mathrm{a}}$ Average $\%$ change $=($ final - initial $) /$ initial $\times 100 \%{ }^{\mathrm{b}}$ A different batch of ASD was used for the study conducted at $40{ }^{\circ} \mathrm{C} / 75 \% \mathrm{RH} / \mathrm{open}$. 


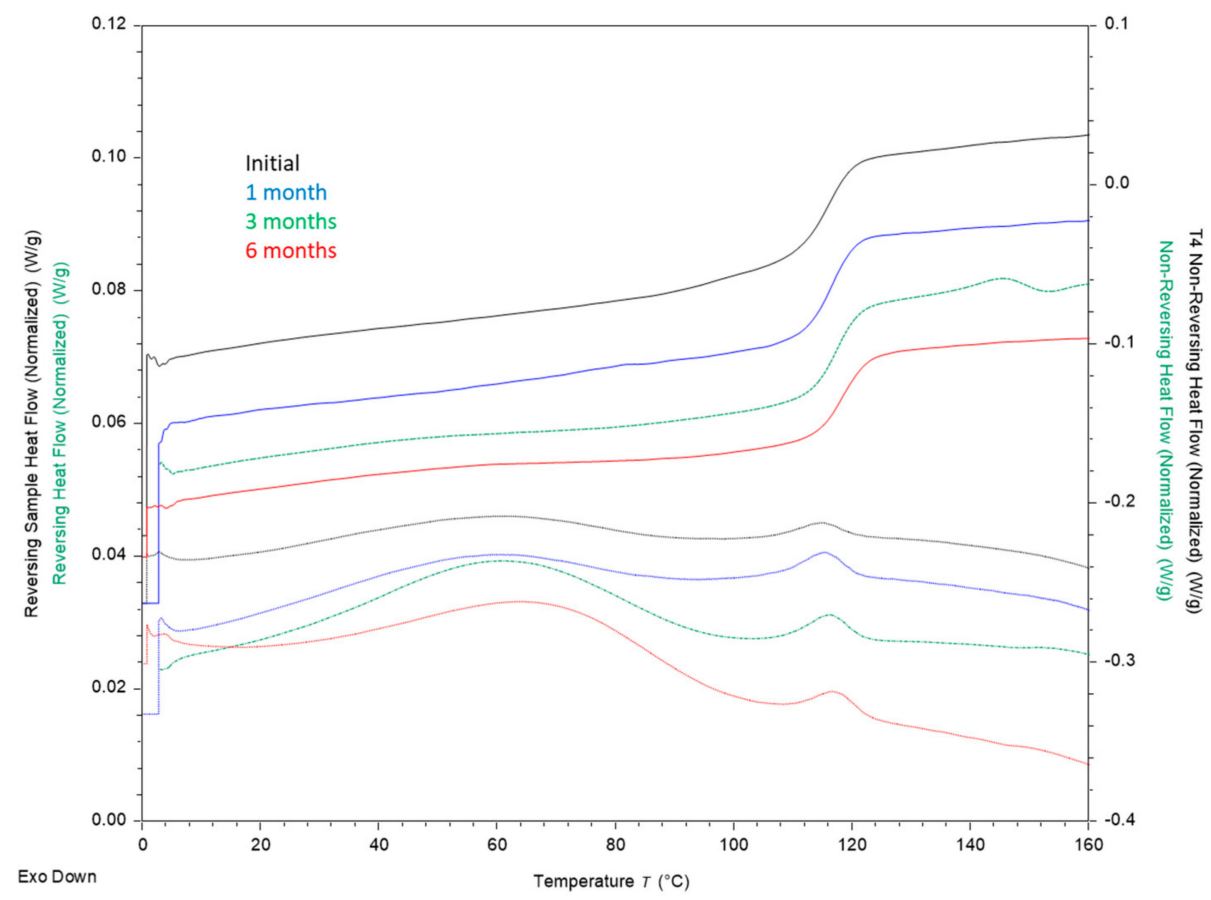

Figure A6. mDSC thermograms of ASD samples before and after storage at $40{ }^{\circ} \mathrm{C} / 75 \% \mathrm{RH} /$ open, demonstrating no change in thermal properties after storage at accelerated conditions.

Table A3. Total impurities of ASD, ASD tablets, and crystalline drug before and after storage for up to 12 weeks as measured by HPLC.

\begin{tabular}{|c|c|c|c|c|c|}
\hline \multirow[b]{2}{*}{ Storage Time } & \multicolumn{5}{|c|}{ Total Impurities (area \%) } \\
\hline & Initial & 2 wk & 4 wk & 5 wk & 12 wk \\
\hline \multicolumn{6}{|c|}{ ASD } \\
\hline $\begin{array}{c}5{ }^{\circ} \mathrm{C} / \text { sealed } \\
\text { with desiccant }\end{array}$ & $0.89 \pm 0.01$ & $0.87 \pm 0.10$ & - & $0.87 \pm 0.07$ & $0.85 \pm 0.00$ \\
\hline $\begin{array}{c}5^{\circ} \mathrm{C} / \text { sealed } \\
25^{\circ} \mathrm{C} / 60 \%\end{array}$ & $0.89 \pm 0.01$ & $0.82 \pm 0.08$ & - & $0.89 \pm 0.00$ & $0.89 \pm 0.01$ \\
\hline $\begin{array}{c}\mathrm{RH} / \text { sealed } \\
\text { with desiccant } \\
25^{\circ} \mathrm{C} / 60 \%\end{array}$ & $0.89 \pm 0.01$ & $0.84 \pm 0.06$ & - & $0.81 \pm 0.05$ & $0.89 \pm 0.01$ \\
\hline $\begin{array}{c}\mathrm{RH} / \text { open, } \\
\text { perforated seal } \\
40{ }^{\circ} \mathrm{C} / 75 \%\end{array}$ & $0.89 \pm 0.01$ & $0.90 \pm 0.07$ & - & $0.95 \pm 0.08$ & $1.15 \pm 0.07$ \\
\hline $\begin{array}{c}\mathrm{RH} / \text { open, } \\
\text { perforated seal }\end{array}$ & $0.60 \pm 0.01$ & - & $1.25 \pm 0.03$ & - & $5.27 \pm 0.08$ \\
\hline \multicolumn{6}{|c|}{ ASD Tablets } \\
\hline $\begin{array}{c}5^{\circ} \mathrm{C} / \text { sealed } \\
\text { with desiccant }\end{array}$ & $0.65 \pm 0.01$ & $0.65 \pm 0.02$ & - & $0.65 \pm 0.06$ & $0.63 \pm 0.01$ \\
\hline $\begin{array}{c}5^{\circ} \mathrm{C} / \text { sealed } \\
25^{\circ} \mathrm{C} / 60 \%\end{array}$ & $0.65 \pm 0.01$ & $0.66 \pm 0.06$ & - & $0.70 \pm 0.15$ & $0.63 \pm 0.01$ \\
\hline $\begin{array}{c}\mathrm{RH} / \text { sealed } \\
\text { with desiccant } \\
25^{\circ} \mathrm{C} / 60 \%\end{array}$ & $0.65 \pm 0.01$ & $0.70 \pm 0.02$ & - & $0.62 \pm 0.00$ & $0.69 \pm 0.00$ \\
\hline $\begin{array}{c}\mathrm{RH} / \text { open, } \\
\text { perforated seal }\end{array}$ & $0.65 \pm 0.01$ & $0.70 \pm 0.05$ & - & $0.74 \pm 0.08$ & $0.82 \pm 0.05$ \\
\hline \multicolumn{6}{|c|}{ Crystalline Drug } \\
\hline $\begin{array}{c}40^{\circ} \mathrm{C} / 75 \% \\
\mathrm{RH} / \text { open, } \\
\text { perforated seal }\end{array}$ & $0.59 \pm 0.00$ & - & $0.70 \pm 0.04$ & - & $0.94 \pm 0.05$ \\
\hline
\end{tabular}


Table A4. Proposed degradants as measured by RP-HPLC-MS analysis.

\begin{tabular}{|c|c|c|c|c|c|}
\hline $\begin{array}{l}\text { Peak Retention } \\
\text { Time (min) }\end{array}$ & $\begin{array}{l}\text { Relative Retention } \\
\text { Time (min) }\end{array}$ & Degradant & $\begin{array}{l}\text { Characteristic Ion } \\
\text { Mass-to-Charge } \\
\text { Ratio }(\mathrm{m} / \mathrm{z})\end{array}$ & $\begin{array}{c}\text { Proposed } \\
\text { Degradation Pathway }\end{array}$ & $\begin{array}{c}\text { Formula Weight } \\
\text { of Proposed } \\
\text { Product (Da) }\end{array}$ \\
\hline 11.05 & 0.65 & Ad1 & 442.6 & $\begin{array}{c}\text { Transamidation with } \\
\text { acetate at pyrrolidine } \\
\text { ring }\end{array}$ & 441.4 \\
\hline 14.79 & 0.87 & Ad2 & 400.6 & $\begin{array}{l}\text { Amide cleavage at } \\
\text { pyrrolidine ring }\end{array}$ & 399.4 \\
\hline 15.09 & 0.89 & Ad3 & 550.8 & $\begin{array}{l}\text { Putative addition } \\
\text { product }\end{array}$ & \\
\hline 16.87 & 0.99 & Ad4 & 484.6 & $\begin{array}{l}\text { Alkyne hydration } \\
\text { Amidation of free }\end{array}$ & 483.5 \\
\hline 17.45 & 1.03 & Ad5 & 532.7 & $\begin{array}{l}\text { amine with } \\
\text { 2-butyne-4-one } \\
\text { fragment }\end{array}$ & 532 \\
\hline 20.23 & 1.19 & Ad6 & $546 / 548$ & $\begin{array}{c}\text { Succinamide } \\
\text { formation at free } \\
\text { amine }\end{array}$ & 548 \\
\hline 23.07 & 1.36 & Ad7 & 457.7 & Unknown & \\
\hline 25.8 & 1.52 & Ad8 & $932.2 / 466.7$ & $\begin{array}{l}\text { Addition and } \\
\text { dimerization }\end{array}$ & \\
\hline 27.9 & 1.64 & Ad9 & $888 / 444$ & Dimerization & \\
\hline
\end{tabular}

${ }^{a}$ Formula weight is typically $\sim 1$ unit lower than the characteristic ion mass-to-charge ratio $(\mathrm{m} / \mathrm{z})$ because each ion picks up an extra H+ during ionization.

Podoll and coworkers have previously reported that the primary mechanisms of degradation for acalabrutinib in the solid state is hydrolysis of the amide and alkyne groups [2]. In the case of the ASD, the rate of hydrolysis may be aided by the increase in water activity in the amorphous form of acalabrutinib relative to the crystal form, coupled with an acidic environment within the ASD particle. As such, protecting the ASD tablets from water by storing them under refrigerated conditions or at room temperature conditions $\left(25^{\circ} \mathrm{C} / 40 \% \mathrm{RH}\right)$ with desiccant mitigates the chemical instability observed when storing the ASD at $40{ }^{\circ} \mathrm{C} / 75 \% \mathrm{RH}$. Although these packaging configurations are less ideal than storage in uncontrolled environments, they are not uncommon for pharmaceutical drug products. Recommended storage conditions for Calquence are storage at 20 to $25^{\circ} \mathrm{C}$ with excursions permitted to 15 to $30^{\circ} \mathrm{C}$ in packaging with no desiccants [1].

Tablets were assayed using the RP-HPLC method upon manufacturing and shortly after the in vivo study (upon receipt of retain tablets from the Covance Laboratories study site), achieving $100-101 \%$ label claim $(n=2)$ and $102-103 \%$ label claim $(n=2)$, respectively.

\section{Appendix A.6. Pharmacokinetic (PK) Study Results}

Profiles of blood plasma drug concentration versus time are shown in Figure A7 for each formulation treatment from 0 to $24 \mathrm{~h}$. Noncompartmental PK results from the acalabrutinib beagle dog study are shown in Table A5. 


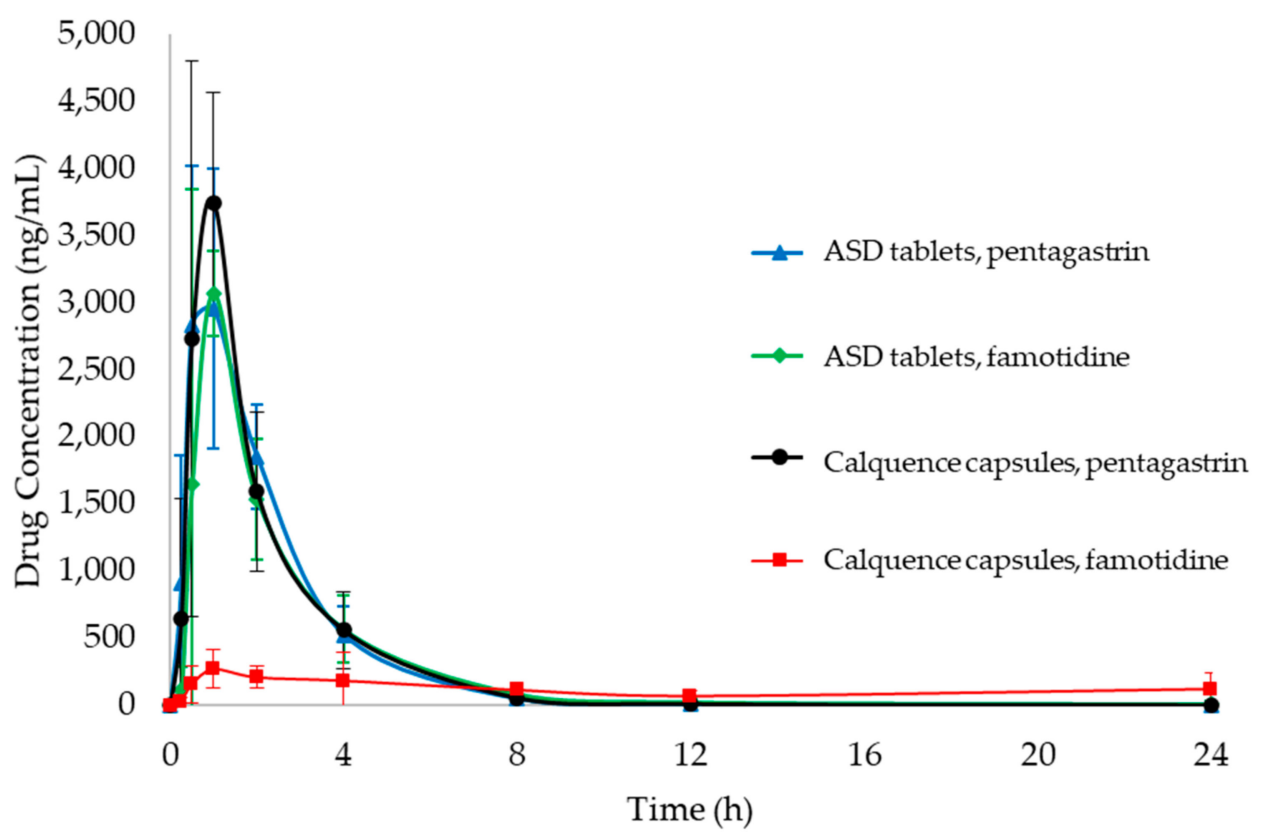

Figure A7. Profiles of blood plasma drug concentration versus time from 0 to $24 \mathrm{~h}$ measured in beagle dogs for ASD tablets and Calquence capsules.

Table A5. Noncompartmental PK results from the acalabrutinib beagle dog study. Data are reported as the mean with a single standard deviation in parentheses.

\begin{tabular}{|c|c|c|c|c|}
\hline Test Article, Pretreatment & $\begin{array}{l}\text { ASD Tablet, } \\
\text { Pentagastrin }\end{array}$ & $\begin{array}{l}\text { ASD Tablet, } \\
\text { Famotidine }\end{array}$ & $\begin{array}{l}\text { Calquence Capsules, } \\
\text { Pentagastrin }\end{array}$ & $\begin{array}{c}\text { Calquence Capsules, } \\
\text { Famotidine }\end{array}$ \\
\hline $\mathrm{AUC}_{0-24}(\mathrm{ng} \mathrm{h} / \mathrm{mL})$ & $8157(1363)$ & $7558(1429)$ & $8363(1199)$ & $2875(1284)$ \\
\hline $\mathrm{AUC}_{0 \text {-inf }}(\mathrm{ng} \mathrm{h} / \mathrm{mL})$ & $8161(1364)$ & 7579 (1423) & $8365(1201)$ & $3112(1415)$ \\
\hline $\begin{array}{l}\mathrm{AUC}_{0 \text {-inf }} p \text {-value (compared to } \\
\text { Calquence, famotidine) }\end{array}$ & $<0.05$ & $<0.05$ & $<0.05$ & $\mathrm{n} / \mathrm{a}^{\mathrm{a}}$ \\
\hline $\begin{array}{l}\text { AUC }_{0 \text {-inf }} p \text {-value (compared to } \\
\text { Calquence capsules, pentagastrin) }\end{array}$ & 0.81 & 0.37 & $\mathrm{n} / \mathrm{a}$ & $<0.05$ \\
\hline
\end{tabular}

${ }^{\mathrm{a}} \mathrm{n} / \mathrm{a}=$ not applicable.

\section{References}

1. Deisseroth, A.B. Calquence FDA Label; U.S. Food and Drug Administration: Silver Spring, MD, USA, 2019; Volume 2020. Available online: https:/ / www.accessdata.fda.gov/drugsatfda_docs/label/2019/210259s006s007lbl.pdf (accessed on 15 March 2021).

2. Pepin, X.J.H.; Moir, A.J.; Mann, J.C.; Sanderson, N.J.; Barker, R.; Meehan, E.; Plumb, A.P.; Bailey, G.R.; Murphy, D.S.; Krejsa, C.M.; et al. Bridging in vitro dissolution and in vivo exposure for acalabrutinib. Part ii. A mechanistic pbpk model for ir formulation comparison, proton pump inhibitor drug interactions, and administration with acidic juices. Eur. J. Pharm. Biopharm. 2019, 142, 435-448. [PubMed]

3. Center For Drug Evaluation and Research. Product Quality Review; Application Number: 210259orig1s000; Center For Drug Evaluation and Research: Silver Spring, MD, USA, 2017.

4. $\quad$ Patel, D.; Bertz, R.; Ren, S.; Boulton, D.W.; Någård, M. A systematic review of gastric acid-reducing agent-mediated drug-Drug interactions with orally administered medications. Clin. Pharmacokinet. 2020, 59, 447-462. [PubMed]

5. Smelick, G.S.; Heffron, T.P.; Chu, L.; Dean, B.; West, D.A.; DuVall, S.L.; Lum, B.L.; Budha, N.; Holden, S.N.; Benet, L.Z.; et al. Prevalence of acid-reducing agents (ara) in cancer populations and ara drug-Drug interaction potential for molecular targeted agents in clinical development. Mol. Pharm. 2013, 10, 4055-4062. [PubMed]

6. Pepin, X.J.H.; Sanderson, N.J.; Blanazs, A.; Grover, S.; Ingallinera, T.G.; Mann, J.C. Bridging in vitro dissolution and in vivo exposure for acalabrutinib. Part i. Mechanistic modelling of drug product dissolution to derive a p-psd for pbpk model input. Eur. J. Pharm. Biopharm. 2019, 142, 421-434.

7. Zhang, L.; Wu, F.; Lee, S.C.; Zhao, H.; Zhang, L. Ph-dependent drug-Drug interactions for weak base drugs: Potential implications for new drug development. Clin. Pharmacol. Ther. 2014, 96, 266-277. 
8. Hens, B.; Tsume, Y.; Bermejo, M.; Paixao, P.; Koenigsknecht, M.J.; Baker, J.R.; Hasler, W.L.; Lionberger, R.; Fan, J.; Dickens, J.; et al. Low buffer capacity and alternating motility along the human gastrointestinal tract: Implications for in vivo dissolution and absorption of ionizable drugs. Mol. Pharm. 2017, 14, 4281-4294.

9. Riethorst, D.; Mols, R.; Duchateau, G.; Tack, J.; Brouwers, J.; Augustijns, P. Characterization of human duodenal fluids in fasted and fed state conditions. J. Pharm. Sci. 2016, 105, 673-681.

10. Shih, G.L.; Brensinger, C.; Katzka, D.A.; Metz, D.C. Influence of age and gender on gastric acid secretion as estimated by integrated acidity in patients referred for 24-h ambulatory ph monitoring. Am. J. Gastroenterol. 2003, 98, $1713-1718$.

11. Blatter, F.; Ingallinera, T.; Barf, T.; Aret, T.; Krejsa, C.; Evarts, J. Solid Forms and Formuations of (s)-4->-Amino-3-(1-(but-2ynoyl)pyrrolidin-2-yl)imidazo[1,5-ajpyrazin- 1-yl)-n-(pyridin-2-yl)benzamide. 2016. Available online: https://patentimages. storage.googleapis.com/5e/4d/3f/0e3e4fb9e1a906/WO2017002095A1.pdf (accessed on 1 March 2021).

12. Van den Mooter, G. The use of amorphous solid dispersions: A formulation strategy to overcome poor solubility and dissolution rate. Drug Discov. Today Technol. 2012, 9, e79-e85.

13. Almeida e Sousa, L.; Reutzel-Edens, S.M.; Stephenson, G.A.; Taylor, L.S. Assessment of the amorphous "solubility" of a group of diverse drugs using new experimental and theoretical approaches. Mol. Pharm. 2015, 12, 484-495.

14. Baghel, S.; Cathcart, H.; O’Reilly, N.J. Polymeric amorphous solid dispersions: A review of amorphization, crystallization, stabilization, solid-state characterization, and aqueous solubilization of biopharmaceutical classification system class ii drugs. $J$. Pharm. Sci. 2016, 105, 2527-2544.

15. Mudie, D.M.; Buchanan, S.; Stewart, A.M.; Smith, A.; Shepard, K.B.; Biswas, N.; Marshall, D.; Ekdahl, A.; Pluntze, A.; Craig, C.D.; et al. A novel architecture for achieving high drug loading in amorphous spray dried dispersion tablets. Int. J. Pharm. X 2020, $2,100042$.

16. Mudie, D.M.; Stewart, A.M.; Biswas, N.; Brodeur, T.J.; Shepard, K.B.; Smith, A.; Morgen, M.M.; Baumann, J.M.; Vodak, D.T. Novel high-drug-loaded amorphous dispersion tablets of posaconazole; in vivo and in vitro assessment. Mol. Pharm. 2020, $17,4463-4472$.

17. Fancher, R.M.; Zhang, H.; Sleczka, B.; Derbin, G.; Rockar, R.; Marathe, P. Development of a canine model to enable the preclinical assessment of ph-dependent absorption of test compounds. J. Pharm. Sci. 2011, 100, 2979-2988.

18. Koziolek, M.; Grimm, M.; Bollmann, T.; Schäfer, K.J.; Blattner, S.M.; Lotz, R.; Boeck, G.; Weitschies, W. Characterization of the gi transit conditions in beagle dogs with a telemetric motility capsule. Eur. J. Pharm. Biopharm. 2019, 136, 221-230.

19. Meyer, J.H.; Dressman, J.; Fink, A.; Amidon, G. Effect of size and density on canine gastric emptying of nondigestible solids. Gastroenterology 1985, 89, 805-813.

20. Dressman, J.B. Comparison of canine and human gastrointestinal physiology. Pharm. Res. 1986, 3, $123-131$.

21. Arndt, M.; Chokshi, H.; Tang, K.; Parrott, N.J.; Reppas, C.; Dressman, J.B. Dissolution media simulating the proximal canine gastrointestinal tract in the fasted state. Eur. J. Pharm. Biopharm. 2013, 84, 633-641.

22. Wang, C.; Zhai, B.; Guo, H.; Wang, P.; Liu, Z.; Gu, H.; Ho, H.; Langguth, P.; Li, K.; Wang, C.; et al. In vivo measurement of gastric fluid volume in anesthetized dogs. J. Drug Deliv. Sci. Technol. 2020, 55, 101488.

23. Smeets-Peeters, M.; Watson, T.; Minekus, M.; Havenaar, R. A review of the physiology of the canine digestive tract related to the development of in vitro systems. Nutr. Res. Rev. 1998, 11, 45-69.

24. Drumond, N.; Stegemann, S. Better medicines for older patients: Considerations between patient characteristics and solid oral dosage form designs to improve swallowing experience. Pharmaceutics 2021, 13, 32.

25. Raber-Durlacher, J.E.; Brennan, M.T.; Verdonck-de Leeuw, I.M.; Gibson, R.J.; Eilers, J.G.; Waltimo, T.; Bots, C.P.; Michelet, M.; Sollecito, T.P.; Rouleau, T.S.; et al. Swallowing dysfunction in cancer patients. Support. Care Cancer 2012, 20, $433-443$.

26. van Leeuwen, R.W.; van Gelder, T.; Mathijssen, R.H.; Jansman, F.G. Drug-drug interactions with tyrosine-kinase inhibitors: A clinical perspective. Lancet Oncol. 2014, 15, e315-e326.

27. Uchiyama, A.A.T.; Silva, P.A.I.A.; Lopes, M.S.M.; Yen, C.T.; Ricardo, E.D.; Mutão, T.; Pimenta, J.R.; Machado, L.M.; Shimba, D.S.; Peixoto, R.D. Proton pump inhibitors and oncologic treatment efficacy: A practical review of the literature for oncologists. Curr. Oncol. 2021, 28, 783-799.

28. Sawicki, E.; Schellens, J.H.; Beijnen, J.H.; Nuijen, B. Inventory of oral anticancer agents: Pharmaceutical formulation aspects with focus on the solid dispersion technique. Cancer Treat. Rev. 2016, 50, 247-263.

29. Herbrink, M.; Nuijen, B.; Schellens, J.H.; Beijnen, J.H. Variability in bioavailability of small molecular tyrosine kinase inhibitors. Cancer Treat. Rev. 2015, 41, 412-422.

30. Gala, U.H.; Miller, D.A.; Williams, R.O. Harnessing the therapeutic potential of anticancer drugs through amorphous solid dispersions. Biochim. Biophys. Acta (BBA) Rev. Cancer 2020, 1873, 188319.

31. Roskoski, R. Properties of fda-approved small molecule protein kinase inhibitors: A 2021 update. Pharmacol. Res. 2021, 165, 105463. [PubMed]

32. Veerman, G.D.M.; Hussaarts, K.; Jansman, F.G.A.; Koolen, S.W.L.; van Leeuwen, R.W.F.; Mathijssen, R.H.J. Clinical implications of food-drug interactions with small-molecule kinase inhibitors. Lancet Oncol. 2020, 21, e265-e279. [PubMed]

33. Pathak, S.M.; Schaefer, K.J.; Jamei, M.; Turner, D.B. Biopharmaceutic ivive-mechanistic modeling of single- and two-phase in vitro experiments to obtain drug-specific parameters for incorporation into pbpk models. J. Pharm. Sci. 2019, 108, 1604-1618.

34. Xu, H.; Vela, S.; Shi, Y.; Marroum, P.; Gao, P. In vitro characterization of ritonavir drug products and correlation to human in vivo performance. Mol. Pharm. 2017, 14, 3801-3814. 
35. Hens, B.; Talattof, A.; Paixão, P.; Bermejo, M.; Tsume, Y.; Löbenberg, R.; Amidon, G.L. Measuring the impact of gastrointestinal variables on the systemic outcome of two suspensions of posaconazole by a pbpk model. AAPS J. 2018, 20, 57.

36. Jamei, M.; Abrahamsson, B.; Brown, J.; Bevernage, J.; Bolger, M.B.; Heimbach, T.; Karlsson, E.; Kotzagiorgis, E.; Lindahl, A.; McAllister, M.; et al. Current status and future opportunities for incorporation of dissolution data in pbpk modeling for pharmaceutical development and regulatory applications: Orbito consortium commentary. Eur. J. Pharm. Biopharm. 2020, $155,55-68$.

37. Grignard, E.; Taylor, R.; McAllister, M.; Box, K.; Fotaki, N. Considerations for the development of in vitro dissolution tests to reduce or replace preclinical oral absorption studies. Eur. J. Pharm. Sci. 2017, 99, 193-201.

38. Kararli, T.T. Comparison of the gastrointestinal anatomy, physiology, and biochemistry of humans and commonly used laboratory animals. Biopharm. Drug Dispos. 1995, 16, 351-380.

39. Zane, P.; Guo, Z.; MacGerorge, D.; Vicat, P.; Ollier, C. Use of the pentagastrin dog model to explore the food effects on formulations in early drug development. Eur. J. Pharm. Sci. 2014, 57, 207-213.

40. Mitra, A.; Kesisoglou, F. Impaired drug absorption due to high stomach ph: A review of strategies for mitigation of such effect to enable pharmaceutical product development. Mol. Pharm. 2013, 10, 3970-3979.

41. Mitra, A.; Kesisoglou, F.; Beauchamp, M.; Zhu, W.; Chiti, F.; Wu, Y. Using absorption simulation and gastric ph modulated dog model for formulation development to overcome achlorhydria effect. Mol. Pharm. 2011, 8, 2216-2223.

42. Litou, C.; Vertzoni, M.; Goumas, C.; Vasdekis, V.; Xu, W.; Kesisoglou, F.; Reppas, C. Characteristics of the human upper gastrointestinal contents in the fasted state under hypo- and a-chlorhydric gastric conditions under conditions of typical drug-Drug interaction studies. Pharm. Res. 2016, 33, 1399-1412.

43. Tutuian, R.; Katz, P.O.; Bochenek, W.; Castell, D.O. Dose-dependent control of intragastric ph by pantoprazole, 10, 20 or $40 \mathrm{mg}$, in healthy volunteers. Aliment. Pharmacol. Ther. 2002, 16, 829-836.

44. Prichard, P.J.; Yeomans, N.D.; Mihaly, G.W.; Jones, D.B.; Buckle, P.J.; Smallwood, R.A.; Louis, W.J. Omeprazole: A study of its inhibition of gastric ph and oral pharmacokinetics after morning or evening dosage. Gastroenterology 1985, 88, 64-69. [PubMed]

45. Podoll, T.; Pearson, P.G.; Evarts, J.; Ingallinera, T.; Bibikova, E.; Sun, H.; Gohdes, M.; Cardinal, K.; Sanghvi, M.; Slatter, J.G. Bioavailability, biotransformation, and excretion of the covalent bruton tyrosine kinase inhibitor acalabrutinib in rats, dogs, and humans. Drug Metab. Dispos. 2019, 47, 145-154. [PubMed] 